UNIVERSIDADE DE SÃO PAULO

ESCOLA DE EDUCAÇÃO FÍSICA E ESPORTE DE RIBEIRÃO PRETO

ISABELLA DOS SANTOS ALVES

Análise do desempenho no goalball:

Propostas de avaliações específicas

RIBEIRÃO PRETO 
ISABELLA DOS SANTOS ALVES

Versão Corrigida

\section{Análise do desempenho no goalball: \\ Propostas de avaliações específicas}

Dissertação apresentada à Escola de Educação Física e Esporte de Ribeirão Preto da Universidade de São Paulo, para obtenção do título de mestra em Ciências, Programa de Pós-Graduação Educação Física e Esporte.

Área de Concentração: Atividade Física e Esporte

Orientador: Prof. Dr. Márcio Pereira Morato

RIBEIRÃO PRETO 
Alves, Isabella dos Santos

Análise do desempenho no goalball: propostas de avaliações específicas. Ribeirão Preto, 2020.

$73 \mathrm{p}$.

Dissertação de Mestrado, apresentada à Escola de Educação Física e Esporte de Ribeirão Preto/USP. Área de concentração: Atividade Física e Esporte

Orientador: Morato, Márcio Pereira.

1. Ciência do esporte. 2. Desempenho tático-técnico. 3. Análise fisiológica. 4. Esporte Paralímpico. 
Nome: ALVES, Isabella dos Santos

Título: Análise do desempenho no goalball: propostas de avaliações específicas

Dissertação apresentada à Escola de Educação Física e Esporte da Universidade de São Paulo para obtenção do título de Mestra em Ciências.

Aprovada em: $\underline{29 \text { de maio de } 2020}$

\author{
Banca Examinadora
}

Prof. Dr. Otávio Luis Piva da Cunha Furtado

Instituição: Universidade de São Paulo/Escola de Educação Física e Esporte

Julgamento: Aprovada,

Prof. Dr. Ciro Winckler de Oliveira Filho

Instituição: Universidade Federal de São Paulo/Depart. Ciências do Movimento Humano

Julgamento: Aprovada,

Prof. Dr. Rafael Pombo Menezes

Instituição: Universidade de São Paulo/Escola de Educação Física e Esporte de Ribeirão Preto

Julgamento: Aprovada, 
Para todos que amam os esportes para pessoas com deficiência. 


\section{AGRADECIMENTOS}

Meu muito obrigado a cada pessoa que passou pela minha vida desde 22 de janeiro de 2018; Aos meus pais, avós e sogros que confiaram no meu trabalho e dedicação;

Á minha irmã, uma mulher inspiradora e, que acredita no meu sonho;

Ao meu namorado, meu grande parceiro da vida, que me motiva a todo instante;

As minhas amigas e amigos, os melhores coadjuvantes da vida acadêmica;

Aos meus grupos de estudos (LAPEEPAJ e GECIFEX) e ao meu coorientador, obrigada pela amizade, orientação e conhecimento;

E, ao meu orientador, o pai que o mestrado me concedeu, obrigada por cada ensinamento, pelos momentos de reflexão e criação, pelos gestos de carinho, humildade e confiança! 


\section{RESUMO}

ALVES, Isabella dos Santos. Análise do desempenho no goalball: propostas de avaliações específicas. 2020. Dissertação (Mestrado em Atividade Física e Esporte) - Escola de Educação Física e Esporte, Universidade de São Paulo, Ribeirão Preto, 2020.

Os propósitos desta dissertação foi desenvolver, aplicar e verificar a reprodutibilidade e validade de avaliações específicas para análise do desempenho tático-técnico (estudo 1) e físico de jogadores de goalball (estudo 2). No estudo 1, a qualidade do desempenho táticotécnico de 24 jogos de elite de goalball foi avaliada e comparada com variáveis contextuais a partir de um sistema de observação específico (Scal-Go). O resultado momentâneo da partida, o resultado final do jogo e o nível das equipes influenciaram e são influenciadores no desempenho apropriado ao inapropriado das equipes. Manter o resultado momentâneo ganhando, propor aplicações de interrupções do jogo em situações que precedem o ataque, arremessar no espaço entre defensores ou entre o defensor e a trave, desempenhar defesas com rápido controle de bola e prevenir a ocorrência de pênaltis foram indicadores de equipes bem sucedidas. No estudo 2, 10 jogadores de goalball foram submetidos a testes, retestes e a um esforço de verificação com intuito de avaliar a reprodutibilidade e validade de um protocolo progressivo específico para jogadores de goalball (Fit-Go). Foi confirmada a reprodutibilidade nas situações teste e reteste do Fit-Go assumindo que: (i) as análises de variância do consumo de oxigênio e frequência cardíaca não apresentaram efeitos da situação e demonstraram favoráveis índices de reprodutibilidade, e; (ii) a percepção subjetiva de esforço obteve variações similares e excelentes índices de reprodutibilidade. $\mathrm{O}$ valor de consumo pico de oxigênio obtido na situação reteste não foi confirmado no esforço de verificação. Contudo, a efetividade do Fit-Go no cumprimento de três ou mais critérios de exaustão confirmaram a funcionalidade do Fit-Go como um protocolo específico de intensidade progressiva para jogadores de goalball.

Palavras-chave: Ciência do esporte. Desempenho tático-técnico. Teste físico. Esporte Paralímpico. 


\begin{abstract}
ALVES, Isabella dos Santos. Performance analysis in Goalball: Specific Assessments Propositions. 2020. Dissertação (Mestrado em Atividade Física e Esporte) - Escola de Educação Física e Esporte, Universidade de São Paulo, Ribeirão Preto, 2020.
\end{abstract}

The main aim was to develop, apply and verify the reproducibility and validity of specific assessments to analyze the tactical-technical (study 1) and physical performance (study 2) of goalball players. In study 1 , the relative quality of tactical-technical performance of 24 elite goalball games was assessed and compared with contextual variables under a specific observation system (Scal-Go). The match status, match outcome and team level presented influence at strongly appropriate to strongly inappropriate team's performance. Maintain winning match status during the game, to propose application of game interruptions in preceding situations, to plan training session to improve throw technique to find the gap between defenders or between defender and the goal post, to perform quick defenses with faster ball control and, prevent penalties shootouts were indicators of successful goalball teams. In the study 2, 10 goalball players underwent tests, retests and a verification effort in order to analyze the reproducibility and validity of a graded protocol for goalball players (FitGo). Reproducibility in the Fit-Go test and retest situations was confirmed, assuming that: (i) the oxygen uptake and heart hate analysis of variance did not show any situation's effects and demonstrated favorable reproducibility rates, and; (ii) rating perceived exertion had similar variations and excellent reproducibility rates. The peak oxygen uptake value obtained in the retest situation was not confirmed in the verification effort. However, the effectiveness of FitGo establishes three or more exhaustion criteria confirmed the Fit-Go functionality as a specific graded protocol for goalball players.

Key-words: Sport science. Match performance. Physical fitness test. Paralympic sport. 


\section{SUMÁRIO}

Página

1. APRESENTAÇÃO 9

1.1 Atividades Acadêmicas e Profissionais 12

1.2 Contextualização 19

1.3 Objetivo Geral 21

$\begin{array}{ll}1.4 \text { Objetivos Específicos } & 21\end{array}$

2. ESTUDO 1222

Marcar gols é determinante para o sucesso de equipes de goalball: 22

Como alcançar isto? 22

3. ESTUDO $2 \quad 42$

Reprodutibilidade e validade de um protocolo progressivo específico para a determinação da potência aeróbia máxima em jogadores de goalball 42

CONSIDERAÇÕES FINAIS

$\begin{array}{ll}\text { APÊNDICE 1 } & 68\end{array}$

$\begin{array}{ll}\text { ANEXO 1 } & 70\end{array}$ 


\section{APRESENTAÇÃO}

Esta dissertação e todos os estudos decorrentes foram realizados com apoio da Coordenação de Aperfeiçoamento de Pessoal de Nível Superior - Brasil (CAPES) - Código de Financiamento 001. Como forma de organizar o conhecimento produzido, o trabalho foi dividido em tópicos: atividades científico-acadêmicas e profissionais desenvolvidas pela autora ao longo do mestrado; contextualização da dissertação, objetivos gerais e específicos que nortearam os dois principais estudos: estudo 1 ("Marcar gols é determinante para o sucesso de equipes de goalball: "Como alcançar isto"); estudo 2 ("Desenvolvimento, aplicação e análise da reprodutibilidade e validade de um protocolo progressivo específico"); e considerações finais a fim de agrupar e contextualizar todas as informações anteriormente discutidas na dissertação. Para uma visualização gráfica da estrutura da dissertação, veja o fluxograma na Figura 1.

O primeiro trabalho específico ("Marcar gols é determinante para o sucesso de equipes de goalball: “Como alcançar isto?”) foi composto por características exploratórias descritivas e obteve como objetivo a análise e qualificação das ações táctico-técnicas de 24 jogos de goalball. Com a adaptação de um sistema observacional de estudos prévios, comparações entre o desempenho das ações e variáveis contextuais foram realizadas. Esse estudo obteve colaboração de alunos de graduação (Leonardo Gomide e Maria Júlia Rocha), pós-graduação (Tatiana Vizú) e docentes (Profs. Drs. Márcio Pereira Morato, Rafael Pombo Menezes e Rodrigo Leal de Queiróz Thomaz de Aquino). Este trabalho foi submetido para a revisão na revista International Journal of Performance Analysis in Sport no dia 18 de maio de 2020 .

O segundo estudo ("Desenvolvimento, aplicação e análise da reprodutibilidade e validade de um protocolo progressivo específico"), compreende características do tipo experimental e propôs o desenvolvimento de um protocolo progressivo específico e as subsequentes análises de reprodutibilidade e validade do teste. Este trabalho foi desenvolvido em colaboração com a equipe de goalball masculino da Associação dos Deficientes Visuais de Ribeirão Preto (ADEVIRP) e o técnico (também aluno de pós-graduação, Jônatas Augusto Cursiol). Além disso, mestrandos da EEFERP (Felipe Alves, Júlia Andreossi e Carlos Dellavequia), e os docentes (Profs. Márcio Pereira Morato, Marcelo Papoti, Carlos Augusto Kalva-Filho e Danilo Bertucci) também colaboraram para o presente estudo. 
Com intuito de diversificar a apresentação do projeto desta dissertação, um vídeo autoexplicativo foi desenvolvido ${ }^{1}$ (scaneie o QR code abaixo ou acesse o link na nota de rodapé para assistir o vídeo).

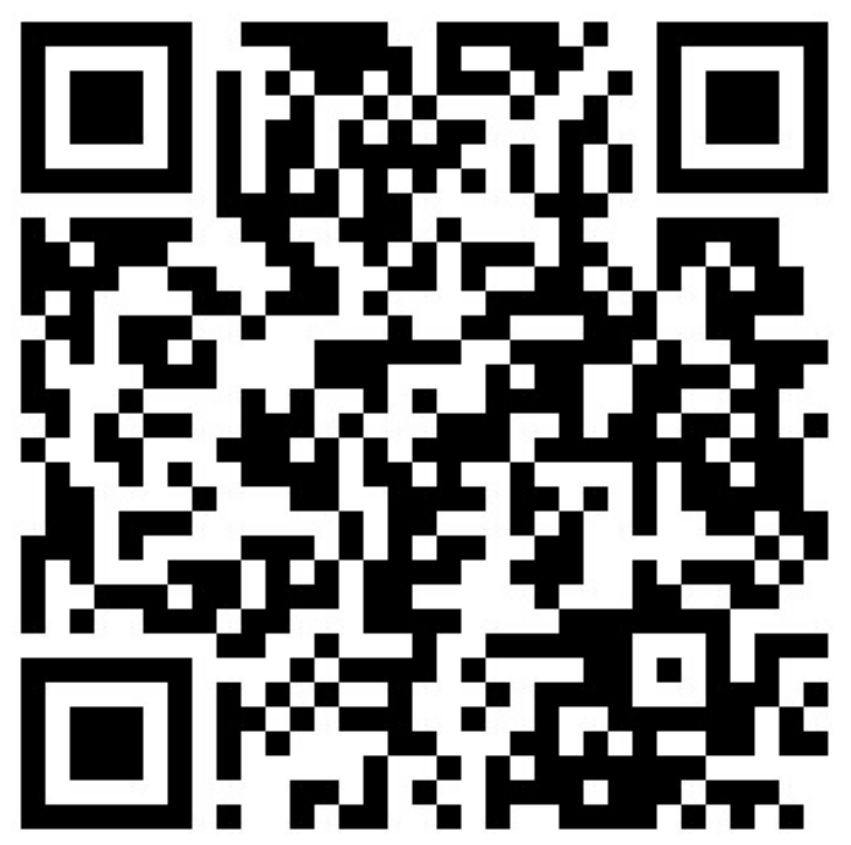

\footnotetext{
${ }^{1}$ Vídeo desenvolvido em parceria com a Cineasta Bruna Del Valhe.
} Link: https://www.youtube.com/watch?v=QDCnvvyeMMU\&t=17s 
Figura 1. Fluxograma do conhecimento produzido na presente dissertação

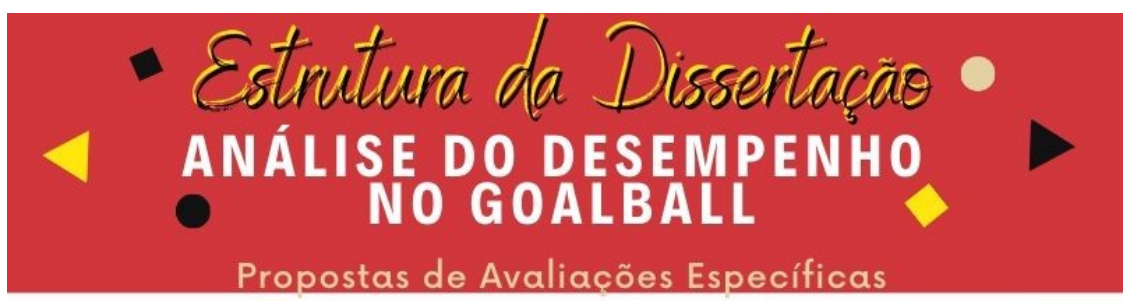

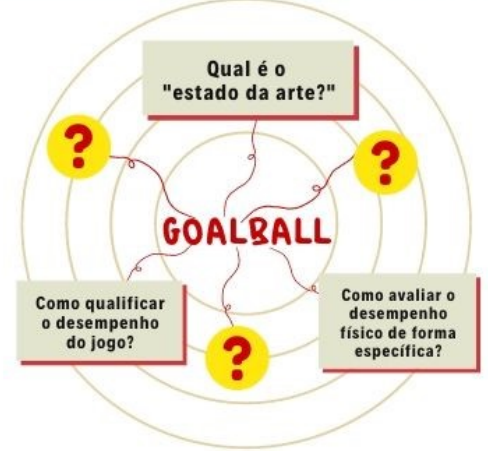

Scal-Go

Sistema observacional para a qualificação do desempenho tático-técnico

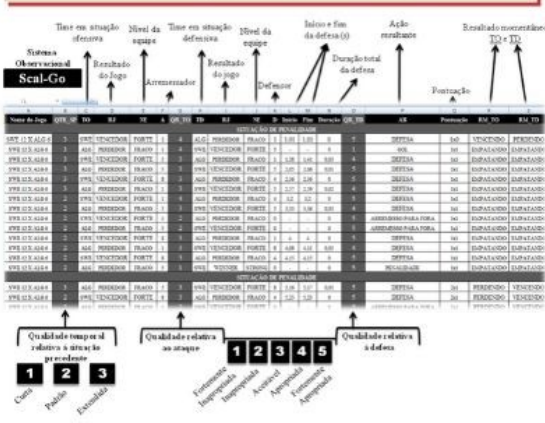

DESEMPENHO FÍsICO

Reprodutibilidade e validade de um protocolo progressivo específico para a determinação da potência aeróbia máxima em jogadores de goalball Avaliação, prescrição e monitoramento são elementos chave no processo de formação atlética. A reprodutibilidade de variáveis fisiológicas foi assumida nas situações teste e reteste do Fit-Go. Ainda, sua efetividade foi confirmada pelo cumprimento de três ou mais critérios de exaustão em $100 \%$ e $80 \%$ dos participantes nas situações teste e reteste, respectivamente. Dessa forma, embora o valor da potência aeróbia obtida na situação reteste não tenha sido confirmado no esforço de verificação, os resultados deste estudo confirmam a funcionalidade do Fit-Go como protocolo progressivo específico para o goalball.

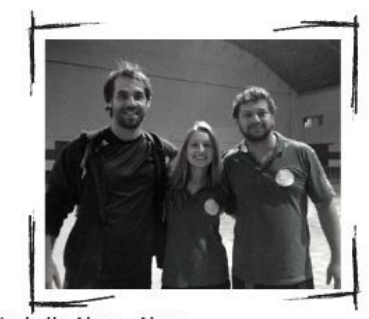

Isabella Alves - Aluna

Prof. Dr. Márcio Morato - Orientador

\section{CONTEXTUALIZACÃo Pág. 19}

O goalball é um esporte coletivo Paralímpico. A fim de promover um desempenho altamente apropriado nos jogos, princípios ofensivos e defensivos ocorrem de maneira cíclica em dois tempos de 12 minutos cronometrados. Dessa forma, saberes referentes ao desempenho tático, técnico e físico podem contribuir para o aprimoramento do rendimento dos atletas por meio de estratégias de treinamento específicas e representativas das demandas do jogo.

\section{DESEMPENHO TÁTICO-TÉCNICO}

\section{PÁG. 22} Marcar gols é determinante para o sucesso de equipes de goalball: "Como alcançar isto?" Duas equipes em uma partida oficial disputam constantemente a obtenção de situações favoráveis ao alcance do sucesso. 0 resultado momentâneo "ganhando" se mostrou uma variável chave para o alto desempenho no jogo. Além disso, a fase defensiva demonstrou desempenho fortemente apropriado em todas as equipes, independentemente do resultado momentâneo, do resultado da partida e do nível das equipes. Estratégias de interrupção do jogo, treinamentos de arremessos entre jogadores ou entre jogadores e a trave, diminuição do tempo de controle da posse de bola na fase defensiva e, a todo o momento, assegurando não cometer penalidades, são fatores que podem contribuir para a obtenção do sucesso por equipes de goalball.

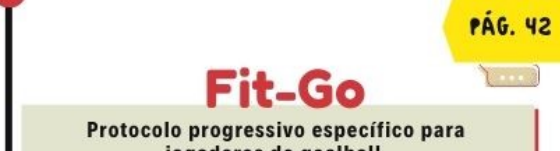

Protocolo progressivo específico para jogadores de goalball

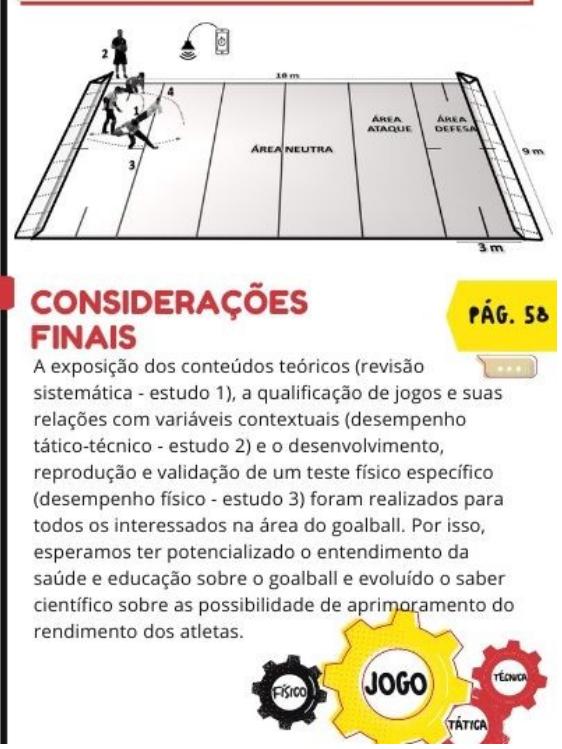

Fonte: Autoria própria. 


\subsection{Atividades Acadêmicas e Profissionais}

Sem saber tamanha importância na época, 2012 foi um ano extremamente decisivo em minha vida. Não só foi o ano que decidi seguir carreira na área de Educação Física (com grande apoio dos meus pais, Andréa e Renato), mas também, foi o ano que desfrutei dos primeiros contatos com pessoas com deficiência em contexto prático. Mas, como assim em contexto prático? Em 2012 participei de aulas gratuitas de Língua Brasileira de Sinais (LIBRAS) e Braille no centro cultural de Lins - SP, minha cidade natal. Em conjunto a isso, ministrei aulas de dança (especificamente hip hop) para um amigo da turma de LIBRAS. Nada faria sentido se esse aluno, o Lucas, não fosse surdo. Conduzir as aulas de dança sobre as vibrações e batidas refletidas pelo ritmo da música foi apaixonante (esse é o melhor adjetivo). Daí em diante, sabia (desejava) que iria trabalhar com pessoas com deficiência, mas certamente não estava ciente que isso me levaria até os dias de hoje, o tão sonhado mestrado.

Após a aprovação no vestibular da FUVEST, iniciei minha graduação em fevereiro de 2013 na Escola de Educação Física e Esporte de Ribeirão Preto, da Universidade de São Paulo (EEFERP-USP). Minhas primeiras atividades científico-acadêmicas iniciaram-se no segundo semestre de 2013. Felizmente, em setembro deste ano, fui contemplada com uma bolsa de estudos pelo Programa de Educação pelo Trabalho para a Saúde (PET-Saúde), sob a orientação da Prof. Dra. Rosalina Aparecida Partezani Rodrigues, da Escola de Enfermagem de Ribeirão Preto da Universidade de São Paulo, com vigência de setembro de 2013 até julho de 2014. Foi ótimo trabalhar com pessoas idosas, mas sabia que esse não seria meu destino na Educação Física. Em conjunto a esse projeto, realizei meus primeiros trabalhos voluntários na EEFERP, atuando como professora de dança do ventre no Projeto de Manutenção do Grupo de Aprendizado e Aperfeiçoamento de Dança Livre do Campus da USP de Ribeirão Preto. Tal atividade foi supervisionada pelo Prof. Dr. Enrico Fuini Puggina e perdurou até o final de 2015 (isto porque, outras oportunidades surgiram ao longo do caminho). Além das atividades supracitadas, ainda no primeiro ano, me integrei aos grupos: Grupo de Estudos e Pesquisas em Análise do Jogo (GEPAJ) liderado pelos Profs. Drs. Márcio Pereira Morato e Rafael Pombo Menezes e, ao Grupo de Estudo em Ciências Fisiológicas e Exercício Físico (GECIFEX) liderado pelos Profs. Drs. Marcelo Papoti e Adelino Sanguez Ramos da Silva. Essa integração com diferentes grupos, pessoas, ideias e motivações me orientaram para novas vertentes, que com certeza, foram essenciais para o "pontapé" inicial na minha trajetória acadêmica. 
A partir disso, me dediquei à leitura periódica de artigos científicos e participação das discussões científico-acadêmicas. Nesse cenário, após conversas e reuniões com dois professores que eu mais admirava (Márcio Morato e Marcelo Papoti), fui orientada a concorrer a uma bolsa de Iniciação Científica. No início eu almejava estudar algo relacionado com "Dança para pessoas com deficiência visual". Certamente havia um resquício da paixão iniciada em 2012. Entretanto, mais paixões surgiram ao longo do caminho acadêmico. Os grupos GEPAJ e GECIFEX me fizeram entender que havia mais vertentes no campo da Educação Física e Esporte. Foi com essa perspectiva, que no final de março de 2014 eu, e os dois professores supracitados escrevemos juntos um projeto de Iniciação Científica. Este, envolvia as especialidades dos professores e minha paixão do exercício físico vinculado à pessoa com deficiência. Tal projeto foi intitulado "Caracterização da participação metabólica em atletas de goalball". Com muito orgulho, ele foi aprovado pelo Programa Institucional de Bolsas de Iniciação Científica (PIBIC), financiado pelo Conselho Nacional de Desenvolvimento Científico e Tecnológico (CNPq), com vigência de agosto de 2014 a julho de 2015, sob a orientação do Prof. Dr. Marcelo e coorientação do Prof. Dr. Márcio. Felizmente, esse trabalho gerou frutos, recebendo o título de Menção Honrosa quando apresentado na Mostra de Destaques do $23^{\circ}$ Simpósio Internacional de Iniciação Científica e Tecnológica da USP - SIICUSP, na área de Ciências da Saúde. Por conseguinte, tal titulação resultou em um convite para apresentação do resumo no $68^{\circ}$ Reunião Anual da Sociedade Brasileira para o Progresso da Ciência, que, nesse ano foi realizado na Universidade Federal do Sul da Bahia, Porto Seguro.

A partir do primeiro contato com a iniciação científica, meu interesse científico expandiu-se ainda mais. Estava ansiosa para pesquisar, ler algo relacionado ao meu tema, apresentar o meu projeto, entre outros. Como forma de complementar o conhecimento gerado pela primeira iniciação científica, iniciei os trabalhos para o desenvolvimento do segundo projeto. Em agosto de 2015 fui contemplada com a bolsa de iniciação científica fomentada pela Fundação de Amparo à Pesquisa do Estado de São Paulo (FAPESP), n ${ }^{\circ}$ do processo 2015/06781-0, agora, sob a orientação do Prof. Dr. Márcio e coorientação do Prof. Dr. Marcelo Papoti, com vigência até julho de 2016. Ambas as iniciações científicas contemplaram análises de aspectos fisiológicos em jogadores de elite de goalball. Com consequente avanço em relação ao primeiro, o segundo projeto permitiu o desenvolvimento das relações entre parâmetros fisiológicos e do desempenho técnico em jogos de goalball. Após a finalização dos trabalhos e consequente apresentação de resumos em congressos científicos e workshop (Congresso Internacional de Educação Física e Motricidade Humana e 
XV Simpósio Paulista de Educação Física, realizado em Rio Claro - SP, em 2015 e 2017; e I Workshop em Fisiologia do Exercício e Rendimento Esportivo, em 2015), além da redação do meu trabalho de conclusão de concurso (que envolveu as duas iniciações científicas), houve a produção de dois artigos científicos. O primeiro já publicado na revista Frontiers in Physiology, e o segundo consta submetido na revista Journal of Visual Impairment \& Blindness:

- AlVES, I. S.; KALVA-FILHO, C. A.; AQUINO, R.; TRAVITZKI, L.; TOSIM, A.; PAPOTI, M.; MORATO, M. P. Relationships between aerobic and anaerobic parameters with game technical performance in elite goalball athletes. Frontiers in physiology, v. 9, 2018.

- AlVES, I. S.; KALVA-FILHO, C. A.; ARRUdA, T. B.; CURSIOL, J. A.; TOSIN, A.; PAPOTI, M.; MORATO, M. P. Reproducibility of sport-specific repeated protocol for anaerobic alactic training in elite goalball athletes. Submetido, 2020.

Adiante na graduação, novas oportunidades surgiram na trajetória acadêmica. No final de 2015 me inscrevi para o processo seletivo do Programa de Mobilidade Internacional Santander: AG USP CANI, na modalidade de graduação sanduíche. Felizmente fui agraciada com a bolsa de estudos com vigência de 180 dias, que resultou no intercâmbio de agosto a dezembro de 2016. Neste período, desenvolvi atividades científico-acadêmicas no Departamento de Nutrição, Exercício e Ciência do Esporte da Universidade de Copenhague, Dinamarca, sob a orientação/supervisão do Prof. Dr. Nikolai Nordsborg e acompanhamento pela aluna de mestrado Janni Enghave. As contribuições dessa parceria foram imensuráveis para minha formação, tanto no sentido profissional, quanto no pessoal. Como produto do meu desempenho em colaborações em experimentos houve a redação de um artigo científico. Este encontra-se em processo de submissão:

- ENGHAVE J.; SOREnSEN V.; VOldSTEDlund C.; ALVES I.; OLSEN N.; NORDSBORG N. Exhaustive knee-extension exercise does not alter indexes of muscle excitability. Em processo de re-submissão, 2020.

Em 2017, ao voltar para a graduação na EEFERP-USP decidi me aprofundar mais nos estudos em esportes para pessoas com deficiência. Integrei-me no Grupo de Estudos e 
Pesquisa em Esporte Paralímpico (GEPEP) sob a coordenação do Prof. Dr. Márcio. Junto a isso, concorri e fui contemplada com uma bolsa PEEG - Programa de Estímulo de Graduação, na qual, tive oportunidade de auxiliar e monitorar alunos da graduação na disciplina de Práticas Esportivas em Educação Física e Saúde, sob a supervisão do Profs. Drs. Márcio Morato e Marcelo Papoti. A monitoria foi a primeira oportunidade de supervisionar alunos de graduação e, com certeza, tal atividade contribuiu ainda mais para fomentar o interesse pela Pós-Graduação.

Após a finalização da monitoria, que perdurou por um semestre, em setembro de 2017 fui agraciada pelo Programa Unificado de Bolsas de Estudos da Escola de Educação Física e Esporte e pude novamente me inserir a uma pesquisa científica. Auxiliei em um projeto de pós-doutorado, intitulado: “Análise dos fatores associados à ocorrência e ao resultado das penalidades no goalball masculino de elite”, sob a orientação do Prof. Dr. Márcio e supervisão do Prof. Dr. Otávio Luis Piva da Cunha Furtado, com vigência até junho de 2018.

Durante a graduação, também realizei estágios profissionais nas empresas "Triple assessoria esportiva" e "Colégio Marista de Ribeirão Preto", nas quais me especializei no treinamento funcional e corrida, e na iniciação esportiva extracurricular infantil, respectivamente. Ambas as empresas, foram importantíssimas na construção do meu currículo profissional, embora, as atividades acadêmicas laboratoriais continuavam sendo mais atrativas a mim. Com isso, estabeleci parcerias com outros laboratórios na EEFERP, que resultaram na colaboração e publicação de quatro artigos científicos:

- Aquino, R.; AlVES, I.; PADIlHA, M. B.; CASANOVA, F.; PUGGINA, E. F.; MAIA, J. Multivariate profiles of selected versus non-selected high level young Brazilian soccer players. Journal of Human Kinetics, v. 60, p. 113-121, 2017.

- AQUINO, R.; ALVES, I. S.; PADILHA, M. B.; GARGANTA, J.; MARQUES, R. F. R. A produção científica acerca do aspecto tático-técnico nos jogos esportivos coletivos: análise dos periódicos brasileiros. Movimento, v. 23, n. 4, p. 1407-1420, 2017. 
- AQuino, R.; PUgGina, E. F.; ALVES, I. S.; GARGAnTA, J. Skill-related performance in soccer: A systematic review. Human Movement, v. 18, n. 5, 2017.

- AQUINO, R.; VIEIRA, L. H. P.; CARLING, C.; MARTINS, G. H. M.; ALVES, I. S.; PUGGINA, E. F. Effects of competitive standard, team formation and playing position on match running performance of Brazilian professional soccer players. International Journal of Performance Analysis in Sport, v. 17, n. 5, p. 1-11, 2017.

Concomitante com as parcerias realizadas, participei da produção de 10 resumos para eventos científicos nacionais e internacionais, sendo oito de primeira autoria. Ministrei cinco palestras relacionadas ao Esporte Paralímpico em sua maioria que é, até os dias de hoje, meu tema de interesse. Durante toda graduação demonstrei um ótimo desempenho acadêmico. Me formei em janeiro de 2018, com média ponderada de 8,3 e sem qualquer reprovação, felizmente. Ainda, vale a pena destacar, que um dos maiores presentes que a Universidade me deu foi a oportunidade de "fazer ciência". Tal oportunidade que me levou em direção ao mestrado.

O processo seletivo do mestrado ocorreu no final de 2017, junto a finalização da graduação. Não foi fácil, mas a paixão plantada em 2012 e os frutos colhidos na graduação me fizeram perceber que o mestrado era o local que eu gostaria de estar. Depois de passar por um processo seletivo, felizmente fui aprovada no Programa de Pós-Graduação da EEFERPUSP e em 22 de janeiro de 2018 me matriculei no mestrado. Desde então, meu objetivo tem sido gerar mais conhecimento sobre o Esporte Paralímpico, atualmente com o foco voltado ao goalball. Especificamente pelo desenho experimental do meu projeto, interesso-me em padronizar novos testes para a modalidade e contribuir de alguma forma para $o$ desenvolvimento tático-técnico e físico do jogo de goalball.

Muitas foram as oportunidades e felicidades alcançados já no meu primeiro ano de mestrado. Por meio de um processo seletivo, fui agraciada com a bolsa de mestrado pela Coordenação de Aperfeiçoamento de Pessoal de Nível Superior (CAPES) no dia 19 de março de 2018. A partir deste momento, com dedicação exclusiva à "vida da Pós-Graduação", foi possível almejar ainda mais meu crescimento profissional e pessoal na vida acadêmica. Ao longo do ano completei 28 créditos em disciplinas e dois créditos pela participação no Estágio Supervisionado em Docência, todas com conceito $\mathrm{A}^{2}$; participei de quatro eventos científicos (sendo dois congressos internacionais, um latino-americano e outro brasileiro); produzi dois

\footnotetext{
${ }^{2}$ Dos 30 créditos adquiridos, seis foram disponibilizados (como créditos excedentes) para posterior aproveitamento no curso de doutorado.
} 
resumos como primeira autora; ministrei quatro palestras (todas relacionados com o Esporte Paralímpico); fui avaliadora (nível júnior) no $26^{\circ}$ Simpósio Internacional de Iniciação Científica e Tecnológica da USP - SIICUSP; participei de 11 cursos e capacitações e; finalmente obtive o aceite do meu primeiro artigo como primeira autora (este, supracitado e advindo das iniciações científicas da graduação). Além disso, participei do Programa de Aperfeiçoamento de Ensino, no qual desenvolvi sob a orientação e supervisão do Prof. Dr. Márcio, atividades relacionadas à docência (i.e. organização do cronograma pré-disciplina; operação técnica em atividades teórico/práticas e didático-pedagógica; contribuição na relação professor/aluno e participação em atividades avaliativas) na disciplina de Educação Física Adaptada (REF0049). Até o fim do ano de 2018, minhas atividades acadêmicas voltaram-se para a redação do projeto e estudos pilotos para a realização do exame de qualificação.

Oito de março de 2019 foi realizado e aprovado (“o tão esperado") exame de qualificação e daí em diante muitas felicidades e trabalhos estavam por vir. Concomitante ao processo do mestrado iniciaram-se outras atividades acadêmicas e profissionais. De janeiro à dezembro de 2019, realizei a Especialização em Atividade Física Adaptada na Faculdade de Educação Física da Universidade Estadual de Campinas. Que experiência incrível! Adquiri, aprimorei e inovei meus conhecimentos sobre a área de atividade física adaptada durante as aulas e obtive uma excelente orientação da Profa. Dra. Maria Luiza Tanure Alves. Felizmente, meu trabalho de conclusão de curso intitulado "Goalball: 73 anos de idade e quase duas décadas de ciências", foi escolhido como o melhor trabalho do ano. Este trabalho, originário (inicialmente) das ideias para esta dissertação, recebeu a colaboração dos Profs. Drs. Márcio Pereira Morato e Otávio Luis Piva da Cunha Furtado e, com adaptações, integrou um entre os 14 capítulos da coleção “Ciências do Esporte e Educação Física: memória, história e produção do conhecimento em 40 anos de Colégio Brasileiro de Ciências do Esporte (CBCE) $)^{3}$ ". Essa "conversa" estabelecida entre a especialização, o mestrado e a colaboração com demais pesquisadores me estimularam ainda mais no desenvolvimento da Pós-Graduação.

Junto a isto, no final do primeiro semestre de 2019, concorri e fui contemplada com uma bolsa de estudo da JASSO (Student Exchange Support Program) e auxílio financeiro EEFERP, para a realização de um curso de curta duração na Universidade de Tsukuba, Japão. Mais uma experiência incrível! Realizei o minicurso intitulado "Collaborative Research Planning” do dia 09 a 17 de julho de 2019. Inicialmente não havia entendido a magnitude de

\footnotetext{
${ }^{3}$ Para mais informações desse estudo que, em grande parte, colaborou para a fundamentação teórica e desenvolvimento desta dissertação, faça o download do capítulo na íntegra no seguinte link: https://repositorio.ufrn.br/jspui/handle/123456789/29073
} 
aprendizados que esta experiência poderia me proporcionar. $\mathrm{Na}$ verdade, este intercâmbio me mostrou mais que lugares, pessoas e culturas diferentes, ele me auxiliou a organizar, planejar, desenvolver e expor ao mundo minha ciência. De novo, que experiência incrível!

Certamente 2019 e início de 2020 foram os períodos mais densos no mestrado. Análises de jogos, coletas de dados, escritas de trabalhos, representação discente da Comissão de Pós-Graduação e Congregação da EEFERP-USP, entre outras atividades, preencheram minhas semanas. Em paralelo a essas atividades, participei de dez cursos, apresentei três resumos como primeira autora em eventos científicos e outros três como coautora. Ainda, ministrei sete palestras e coorientei dois trabalhos de conclusão de curso: "Relações entre classe funcional e eficácia do arremesso por zona da quadra no basquetebol em cadeira de rodas" do aluno Mateus Ribeiro (TCC finalizado em 2019 - submissão do artigo em andamento) e "Dança e afetividade de pessoas com síndrome de down: uma revisão sistemática" da aluna Rebecca Paiva (monografia em andamento). Eu adorei (co)orientar.

Finalmente, no último semestre de 2019 realizei o curso intitulado "Docência do Ensino Superior: Uma Primeira Aproximação”. A compreensão da Universidade, o entendimento dos perfis de alunos, as possibilidades de didática em sala de aula e, principalmente, os desafios e objetivos como professora foram destacados no curso. O curso foi extremamente importante para minha formação. Contudo, compreendi que toda minha trajetória, vivenciada desde 2012, foi minha grande aproximação do ensino superior. Quero me aproximar cada vez mais do ensino, pesquisa e extensão da área que eu realmente amo: atividade física adaptada. 


\subsection{Contextualização}

O esporte em estudo é o goalball, uma modalidade desenvolvida para fins de reabilitação de soldados advindos da Segunda Guerra Mundial (AMORIM et al., 2010). Em sua criação, o goalball não foi concebido de adaptações de outros esportes, sendo elaborado especialmente para pessoas cegas e com baixa visão em 1946, na Alemanha (TOSIM et al., 2008). A contar da sua primeira aparição nos Jogos Paralímpicos de Toronto 1976, até os Jogos Paralímpicos do Rio 2016, houve um aumento substancial no número de países (de 8 para 14) e atletas participantes (de aproximadamente 5 para 119) ${ }^{4}$. Desde então, houve uma massificação da prática do goalball, assim como de outras modalidades Paralímpicas, que juntas proporcionam um aumento da frequência na participação em eventos internacionais (VANLANDEWIJCK, 2006) demonstrando a busca pelo alto rendimento.

Junto a isso, e como parte da evolução histórica, a ciência vem acompanhando discretamente a disseminação da modalidade. Embora tenha sido mostrado na literatura que entre os 50 artigos mais citados de 1993 a 2014, no âmbito dos esportes adaptados, um total de $30 \%$ dos trabalhos investigaram aspectos relacionados à competição e ao treinamento esportivo, apenas 4\% analisam esportes para pessoas com deficiência visual (KHOO; LI; ANSARI, 2018). O mesmo é verificado no cenário Brasileiro, apenas 3\% das publicações sobre os aspectos tático-técnicos nos jogos esportivos coletivos têm como objeto de estudo o esporte adaptado. Destes, somente $0,61 \%$ representam as pesquisas relacionadas ao goalball, afirmando a escassez de fundamentação teórica na área e a necessidade de mais estudos não só para a comunidade científica, mas também para os profissionais atuantes na prática do ensino e treinamento do esporte (AQUINO et al., 2017).

O propósito central do jogo de goalball é realizar mais gols que o adversário. Dessa forma, a vitória é obtida com 10 gols de diferença ou pelo alcance de uma maior pontuação ao final de dois tempos de 12 minutos cronometrados, com possibilidade de prorrogação. Durante este período, três atletas de cada lado da quadra realizam ações ofensivas e defensivas de forma cíclica (MORATO; GOMES; ALMEIDA, 2012). Na dimensão ofensiva, a equipe controla a posse de bola, prepara o ataque e um jogador arremessa a bola em direção

\footnotetext{
4 Informações obtidas no site do International Paralympic Committee (https://www.paralympic.org/toronto-1976/results/goalball e https://www.paralympic.org/rio2016/results/goalball) acessado em 29 de fevereiro de 2020. A contagem do número de participantes envolvidos no ano de 1976 é referentes aos enunciados oficiais obtidos em livros e em demais resultados de jogos. Por isso, a estatística total de participantes pode conter imprecisões causadas pela falta de documentação oficial.
} 
ao gol adversário. A partir disso, a equipe oponente prepara-se para a defesa, realizando o balanço defensivo seguido da leitura da trajetória da bola e da interceptação da mesma (MORATO; GOMES; ALMEIDA, 2012; NASCIMENTO; CAMARGO, 2012). Diante desse contexto organizacional de ataque e defesa (MORATO; GOMES; ALMEIDA, 2012), sem característica de invasão entre equipes, há uma relação entre aspectos tático-técnicos e físicos, além de outras dimensões (e.g. psicológicas) (EDDY; MELLALIEU, 2003; STAMOU et al., 2007).

De fato, o desempenho em jogo é influenciado pelo perfil físico dos jogadores (ALVES et al., 2018) e a avaliação destas dimensões é um importante indicador para o mapeamento do perfil dos atletas e das equipes. Entretanto, quando a literatura científica é consultada para a compreensão desses aspectos (desempenho em jogo e aspectos físico) poucas pesquisas são encontradas (ALVES et al., 2018; BOWERMAN et al., 2011; CALISKAN et al., 2011; ÇOLAK et al., 2004; FURTADO et al., 2016; GOULARTSIQUEIRA et al., 2018; GULICK; MALONE, 2011; KARAKAYA et al., 2009; LINK; WEBER, 2018; MOLIK et al., 2015; MORATO; GOMES; ALMEIDA, 2012; MORATO et al., 2017; STAMOU et al., 2007). Destes, apenas três estudos propuseram avaliações específicas para o desempenho tático-técnico (MORATO et al., 2017) e físico (GOULARTSIQUEIRA et al., 2018; GULICK; MALONE, 2011) de jogadores de goalball.

Frente ao exposto, algumas perguntas nortearam o desenvolvimento dos dois estudos na presente dissertação: (i) Existem testes válidos para a análise do desempenho tático-técnico e físico no goalball?; (ii) Este desempenho é influenciado por variáveis contextuais?; e, (iii) Um teste físico em quadra, com ações específicas do jogo e utilização da bola, é reprodutível e válido para avaliar a potência aeróbia de jogadores? Essas e outras perguntas refletem os questionamentos quanto as necessidade de parâmetros para entender e aplicar o conhecimento já produzido sobre a modalidade, além de propor novas abordagens para avaliar, prescrever e monitorar o treinamento, a fim de aprimorar o desempenho individual e das equipes de goalball. 


\subsection{Objetivo Geral}

Desenvolver, aplicar e verificar a validade e a reprodutibilidade de avaliações específicas para análise do desempenho tático-técnico (estudo exploratório-descritivo) e físico (estudo experimental) em jogadores de goalball.

\subsection{Objetivos Específicos}

- Desenvolver, aplicar e analisar a validade de um sistema de qualificação das ações no goalball. Isto, com premissa para a descrição da pluralidade de ações apropriadas à inapropriadas durante o jogo e suas possíveis influências por variáveis contextuais;

- Desenvolver, aplicar e analisar a reprodutibilidade e validade de um protocolo progressivo específico para a determinação da potência aeróbia em jogadores de goalball. 


\section{ESTUDO 1}

\section{Marcar gols é determinante para o sucesso de equipes de goalball: Como alcançar isto?}

\section{INTRODUÇÃO}

Fazer mais gols que o adversário é determinante para atingir o sucesso no goalball. Isto é obtido a partir de dez gols de diferença ou superando o número de gols do oponente durante dois tempos de 12 minutos cronometrados (AMORIM et al., 2010; ÇOLAK et al., 2004; IBSA, 2019). Ser bem sucedido durante o ataque significa que os princípios ofensivos (controle da bola, preparação do ataque e o arremesso) (MORATO; GOMES; ALMEIDA, 2012) foram executados de maneira apropriada e resultaram no gol ou, ainda, podem influenciar negativamente a fase defensiva do oponente. Neste sentido, os princípios defensivos (balanço defensivo, leitura da trajetória da bola e interceptação da bola) (MORATO; GOMES; ALMEIDA, 2012) podem ser prejudicados e propiciarem um desempenho inapropriado ou podem consistir em ações condizentes com a necessidade da fase, contribuindo para o desempenho das ações seguintes. Isto, considerando que a equipe se auto-organiza de acordo com a situação do jogo.

Essa complexidade de elementos expostos em fases (ou seja, ataque, defesa e transições) em um sistema de jogo cíclico, sugere aos treinadores como entender e proceder para aplicar o treinamento para jogadores de goalball (MORATO et al., 2017a; MORATO; GOMES; ALMEIDA, 2012). No entanto, é necessário compreender profundamente a diversidade de ações e a pluralidade de desempenhos apropriados aos inapropriados do jogo. Isto, não apenas descrevendo as possibilidades de ações em cada fase ofensiva, defensiva e suas respectivas transições, mas também, qualificando tais desempenhos com procedimentos reprodutíveis e válidos para oportunizar a avaliação do perfil tático-técnico (COSTA et al., 2011), que permanece pouco conhecido na literatura do goalball.

Os indicadores de desempenho são amplamente utilizados para avaliar o rendimento das ações individuais e das equipes (HUGHES; BARTLETT, 2002). Estes, implementados em um sistema observacional baseado em observação empírica, comportam uma análise notacional (O'DONOGHUE, 2010), geralmente requerida por treinadores e analistas de desempenho. Os insights sobre perspectivas estruturais da análise notacional no goalball 
foram evidenciados anteriormente na literatura. Com base nos critérios de exaustividade (O’DONOGHUE, 2010), todas as possibilidades de ações ofensivas e defensivas disponíveis ao longo do jogo de goalball foram categorizadas quantitativamente e qualitativamente (MORATO et al., 2017a). De fato, alguns destes indicadores já provaram aumentar a probabilidade de marcar gols. Por exemplo, arremessos mais intensos (e.g maior velocidade do atacante e da execução do arremesso) (BOWERMAN et al., 2011; MONEZI et al., 2018; MORATO et al., 2017b) em direção paralela, usando a técnica de arremesso com giro e em alvos apropriados (i.e. entre defensores) estão relacionados à pontuação do gol (LINK; WEBER, 2018). Além disso, a acuidade visual se mostra também como um fator a ser administrado no processo de ensino-aprendizagem do goalball. Arremessos por jogadores com baixa visão e defesa por atletas cegos têm maior probabilidade de serem bem sucedidos, uma vez que resíduos visuais podem contribuir para um alto desempenho do ataque e defesa, respectivamente (MOLIK et al., 2015). Todas essas características que, possivelmente, contribuem para um maior rendimento, devem ser planejadas para um indivíduo e uma equipe. Isto, como premissa para a elaboração de condições favoráveis à obtenção do sucesso.

O jogo de goalball é produto das possibilidades de ação e de suas interações com o oponente e o ambiente (MORATO; GOMES; ALMEIDA, 2012), dentro de um sistema dinâmico e imprevisível (MCGARRY et al., 2002; SILVA et al., 2013). Dessa forma, variáveis contextuais (e.g. níveis das equipes e resultado momentâneo) podem influenciar o desempenho dos times e, consequentemente, o resultado final do jogo (TAYLOR et al., 2010, 2008) e são consideradas indicadores convenientes para categorizar equipes bem e mal sucedidas durante uma competição (CASTELLANO; CASAMICHANA; LAGO, 2012; TAYLOR et al., 2008). Apesar do viés em classificar uma equipe em forte ou fraca por seu respectivo rendimento em um único torneio, essas variáveis contextuais apresentaram influência significativa no desempenho esportivo (ALMEIDA; FERREIRA; VOLOSSOVITCH, 2014; TAYLOR et al., 2008) e são necessárias para orientar o treinamento e a estratégia competitiva das equipes (TAYLOR et al., 2010).

Até o momento, nenhum artigo descreveu e comparou essas variáveis contextuais em jogos de goalball. Para contribuir para a qualificação do perfil tático-técnico (compreensão da pluralidade de ações apropriadas ou inapropriadas) e suas possíveis influências por variáveis contextuais, o objetivo do presente estudo foi duplo: (i) descrever o intervalo de desempenho entre ações fortemente inapropriadas à fortemente apropriadas; e (ii) comparar esse intervalo com variáveis contextuais (i.e. nível da equipe, resultado da partida e resultado momentâneo). 


\section{MÉTODOS}

\section{Amostra de jogos}

O método de observação sistemática não participante no contexto do jogo foi utilizado como abordagem científica das análises (ANGUERA; MENDO, 2013; THOMAS; NELSON; SILVERMANN, 2012). A amostra foi composta por 24 gravações em vídeo de partidas de goalball masculino dos Jogos Paralímpicos Rio 2016. Foram excluídas quatro partidas das análises por não preencherem os critérios de inclusão: gravação do jogo completa em vídeo (n =1), igualdade numérica de $3 \times 3$ jogadores $(n=1)$ e a duração do jogo oficial, sem vitórias com dez gols de vantagem por uma equipe $(n=2)$. A gravação dos vídeos foi realizada e compartilhada por analistas de desempenho e pesquisadores que receberam permissão para gravação pela Federação Internacional de Esportes para Cegos (IBSA). O presente estudo foi aprovado pelo Comitê de Ética em Pesquisa para Seres Humanos da Escola de Educação Física e Esporte, Ribeirão Preto, Brasil (CAAE: 93692318.0.0000.5659 - Anexo 1) e foi conduzido de acordo com a declaração de Helsinki.

\section{Procedimentos}

Três estágios compuseram o estabelecimento do sistema de qualificação do desempenho das ações no goalball, denominado Scal-Go: desenvolvimento do sistema observacional, confiabilidade e validade do sistema. O primeiro estágio compôs a definição dos elementos constituintes do sucesso e fracasso durante o ciclo de interação situação precedente-ataque-defesa no goalball. Em seguida, três observadores estabeleceram e concordaram com os critérios de observação sistemática e contribuíram para o estágio de confiabilidade inter e intra-observadores. A validade foi estabelecida usando dois postulados: confiabilidade e validade de conteúdo (CRONBACH, 1988; O’DONOGHUE, 2010). 


\section{Desenvolvimento do sistema}

O Scal-Go foi proposto para qualificar cada fase do ciclo de interações: situação precedente-ataque-defesa. Para isso, foi projetado um sistema observacional específico em planilha ad hoc no Microsoft巴 Excel, compreendendo as seguintes variáveis (Figura 2.1): nome do jogo, time em situação ofensiva (TO), arremessador (A), time em situação defensiva (TD), defensor (D), resultado da partida (RP), nível da equipe (NE), pontuação, resultado momentâneo do time em situação ofensiva (RM_TO) e defensiva (RM_TD); qualidade temporal relativa à situação precedente (QTR_SP), qualidade relativa ao ataque (QR_A), início / fim (tempo inicial do primeiro contato defensivo com a bola até o reestabelecimento da posse de bola), duração total da defesa, qualidade relativa à defesa (QR_D), ação resultante (AR). Essa sequência foi projetada assegurando a auto-organização regular do jogo de goalball (MORATO; GOMES; ALMEIDA, 2012).

O nome do jogo foi designado pelos nomes abreviados das equipes e suas respectivas pontuações (e.g. SWE 12 X ALG 6, para disputa entre Suécia e Argélia). O controle da posse da bola em jogo delimitou os times em situação ofensiva ou defensiva. Para isso, foram inseridos os nomes abreviados das equipes (e.g. TO $=$ SWE e TD = ALG). O arremessador e defensor foram registrados pelo número impresso no uniforme do jogador. $\mathrm{O}$ arremessador foi designado pelo atleta que arremessou a bola em direção ao oponente, enquanto o defensor para quem estabeleceu o primeiro contato defensivo com a bola. 
Figure 2.1. Sistema observacional para qualificação do desempenho das ações no goalball (Scal-Go).

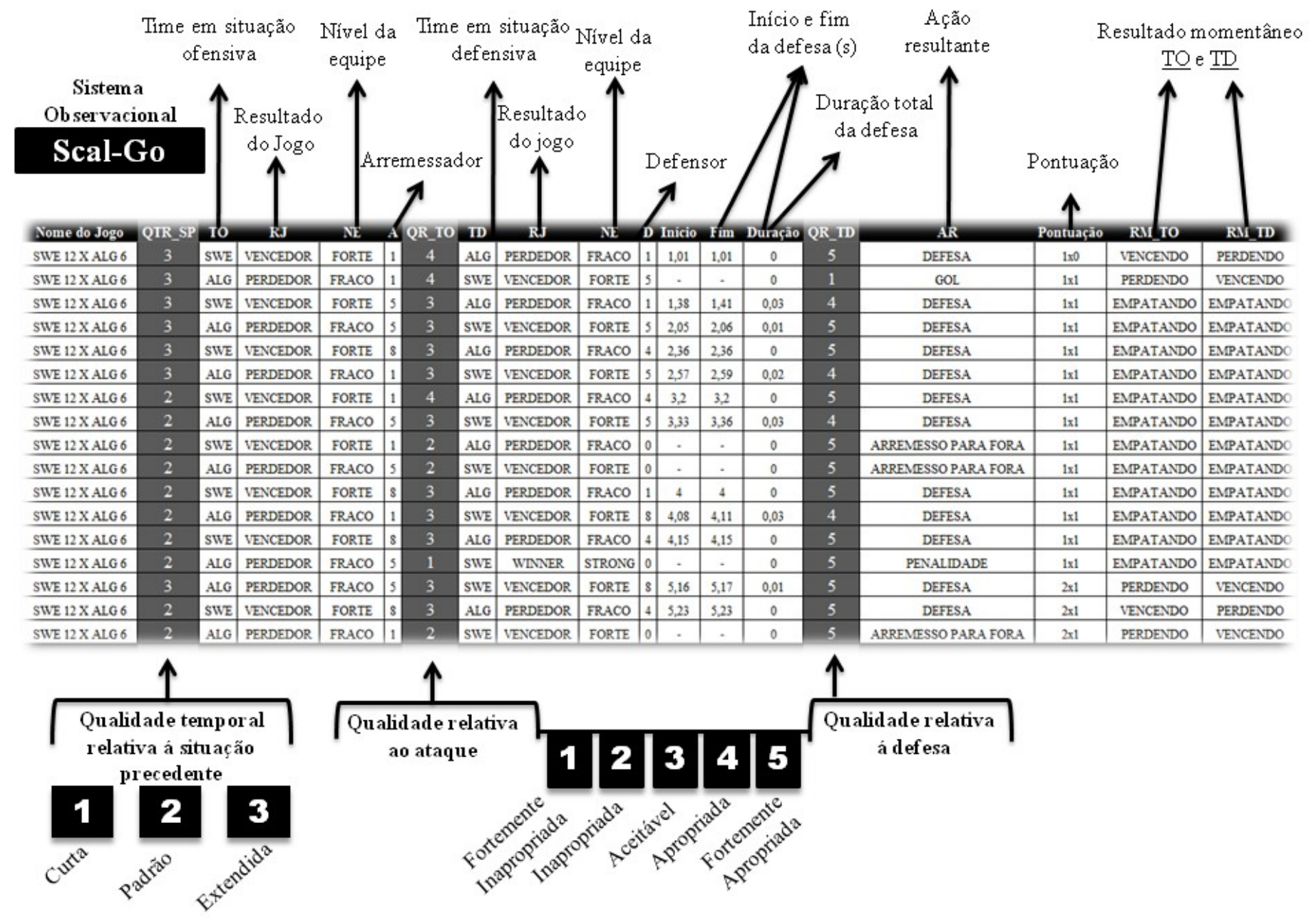

Fonte: Autoria própria. 


\section{Variáveis dependentes e independentes}

As variáveis chamadas qualidade temporal relativa à situação precedente, qualidade relativa ao ataque e qualidade relativa à defesa foram consideradas variáveis dependentes. Utilizando de uma escala de likert, uma sequência de preenchimento lógico foi criada e um número entre 1 à 3 foi designado para categorizar temporalmente a situação precedente [curta (1), padrão (2) e extensa (3); Tabela 2.1]. Para as qualificações do ataque e a defesa um número entre 1 e 5 foi alocado [fortemente inapropriado (1), inapropriado (2), aceitável (3), apropriado (4) e fortemente apropriado (5); Tabela 2.2] para categorizar a eficácia de ambas as fases ofensivas e defensivas. Isto, considerando a probabilidade de marcar um gol (devido a estudos e discussões prévias do grupo de pesquisa - textos ainda não publicados) e as ações resultantes da interação entre ataque e defesa (i.e. gol, defesa do arremesso adversário, bloqueio do arremesso adversário para fora, arremesso para fora, penalidade ou infração).

Importante destacar que o início / fim da defesa e sua duração total foram utilizados para estabelecer o tempo de controle da bola pela equipe defensora e consequentemente a qualidade defensiva da equipe. Além disso, a qualidade relativa à defesa após situações de bloqueio do arremesso adversário para fora, foi considerado de duas formas: (i) se a bola ultrapassou a linha lateral "line out”, o final da defesa foi considerado pelo apito de sinalização do árbitro pela saída da bola; ou (ii) nos casos em que não há saída da bola pela linha "line out", o final da defesa foi considerado pelo primeiro contato da bola na quadra após a reposição pelo árbitro de linha.

Três variáveis independentes foram incluídas neste estudo (AQUINO et al., 2020; LAGO, 2009): (i) nível da equipe; (ii) resultado da partida; e (iii) resultado momentâneo. A variável contextual denominada nível da equipe foi assinalada de acordo com a classificação final na competição: equipes fortes (primeira à quarta colocação, $n=2499$ eventos) e equipes fracas (quinta à décima colocação, $\mathrm{n}=2028$ eventos). $\mathrm{O}$ resultado da partida no placar final de cada jogo [equipes vencedoras $(\mathrm{n}=2219$ eventos) $v$ s. perdedoras $(\mathrm{n}=2308)$ ]. O resultado momentâneo foi considerado de acordo com a situação da equipe no momento da entrada de dados na planilha [i.e. vencendo $(\mathrm{n}=1801$ eventos $)$ vs. empatando $(\mathrm{n}=824$ eventos $) v s$. perdendo $(\mathrm{n}=1902$ eventos $)]$. 
Tabela 2.1. Qualidade temporal relativa à situação precedente e seus respectivos valores de confiabilidade

Qualidade Temporal Relativa

\begin{tabular}{|c|c|c|c|c|}
\hline \multirow{2}{*}{$\begin{array}{c}\text { Curta } \\
1\end{array}$} & \multirow{2}{*}{$\begin{array}{c}\text { Padrão } \\
2 \\
\end{array}$} & \multirow{2}{*}{$\begin{array}{c}\text { Extensa } \\
3\end{array}$} & \multicolumn{2}{|c|}{ Confiabilidade } \\
\hline & & & Inter & Intra \\
\hline \multicolumn{5}{|c|}{ Situação Precedente } \\
\hline $\begin{array}{c}\text { Contra-ataque (sem o retorno } \\
\text { ofensivo, atletas arremessaram a } \\
\text { bola no do mesmo local e instante } \\
\text { em que defenderam) }\end{array}$ & $\begin{array}{c}\text { Início após infração (e.g. ball over) ou } \\
\text { ciclo regular de ataque-defesa (i.e. } \\
\text { sem contra-ataque ou interrupção do } \\
\text { jogo) }\end{array}$ & $\begin{array}{c}\text { Interrupção oficial } \\
\text { (i.e. team, official's or medical time } \\
\text { out or substitutions), início e intervalo } \\
\text { do jogo, situação após ocorrência de } \\
\text { gol ou penalidade }\end{array}$ & $0,794-0,919$ & 0,974 \\
\hline
\end{tabular}


Tabela 2.2 Qualidade relativa ao ataque e à defesa e seus respectivos valores de confiabilidade

\begin{tabular}{|c|c|c|c|c|c|c|}
\hline \multicolumn{5}{|c|}{ Qualidade Relativa } & \multirow{2}{*}{\multicolumn{2}{|c|}{ Confiabilidade }} \\
\hline Fortemente & \multirow{2}{*}{$\begin{array}{c}\text { Inapropriado } \\
2\end{array}$} & \multirow{2}{*}{$\begin{array}{c}\text { Aceitável } \\
3\end{array}$} & \multirow{2}{*}{$\begin{array}{c}\text { Apropriado } \\
4\end{array}$} & \multirow{2}{*}{$\begin{array}{l}\text { Fortemente Apropriado } \\
\qquad 5\end{array}$} & & \\
\hline 1 & & & & & Inter & Intra \\
\hline & & Ataque & & & & \\
\hline \multirow[t]{2}{*}{$\begin{array}{l}\text { Pênalti; } \\
\text { gol contra }\end{array}$} & $\begin{array}{c}\text { Infrações } \\
\text { (i.e. "pass out"ou } \\
\text { "prepature throw"); } \\
\text { arremesso para fora; } \\
\text { arremesso de segurança }\end{array}$ & $\begin{array}{c}\text { Arremesso no } \\
\text { segmento corporal } \\
\text { central do defensor } \\
\text { (braços, cabeça, } \\
\text { peito, quadril, coxa e } \\
\text { joelho) }\end{array}$ & $\begin{array}{c}\text { Arremesso } \\
\text { nos segmentos } \\
\text { corporais extremos do } \\
\text { defensor (antebraços, } \\
\text { mãos, pernas e pés) }\end{array}$ & $\begin{array}{l}\text { Arremesso ao gol entre } \\
\text { os defensores; arremesso } \\
\text { ao gol entre os } \\
\text { defensores e a trave }\end{array}$ & $0,850-0,915$ & 0,927 \\
\hline & & Defesa & & & & \\
\hline Gol sofrido & $\begin{array}{c}\text { Infração } \\
\text { (i.e. "ball over") }\end{array}$ & $\begin{array}{l}\text { Tempo de controle da } \\
\text { bola } \geq 4 \text { segundos }\end{array}$ & $\begin{array}{l}\text { Tempo de controle da } \\
\text { bola entre } 3 \text { e } 2 \\
\text { segundos }\end{array}$ & $\begin{array}{l}\text { Tempo de controle da } \\
\text { bola } \leq 1 \text { segundos; } \\
\text { arremesso adversário para } \\
\text { fora; pênalti adversário }\end{array}$ & $0,752-0,820$ & 0,846 \\
\hline
\end{tabular}




\section{Confiabilidade e validade}

O índice Kappa foi utilizado para a quantificação das variáveis categóricas (FLEISS; LEVIN; PAIK, 2003) e para análise de confiabilidade (HOPKINS, 2000; O’DONOGHUE, 2010). Três jogos randomizados (12,5\% do tamanho da amostra) compreenderam a confiabilidade interobservadores (três pesquisadores: I.S.A., M.J.R. e L.L.G.). Um jogo (4,2\% do tamanho da amostra) compôs a confiabilidade intraobservador (um pesquisador: I.S.A.) com intervalo de 15 dias entre as duas observações (DONOGHUE, 2010). Altos níveis de concordância (Tabelas 3.1 e 3.2) foram obtidos para as variáveis (qualidade temporal relativa à situação precedente, time em situação ofensiva, arremessador, qualidade relativa ao ataque, time em situação defensiva, defensor, qualidade relativa à defesa, ações resultantes e pontuação), variando de 0,752 a 0,992 (interobservador) e de 0,846 e 1.000 (intraobservador) (ALTMAN, 1991).

O estabelecimento da validade foi realizado usando postulados de confiabilidade e validade de conteúdo (CRONBACH, 1988; O’DONOGHUE, 2010). Conforme mencionado acima, a confiabilidade inter e intraobservador foram testadas e assumidas com alto nível de consistência observacional, operacional e temporal. A validade do conteúdo foi alcançada ao garantir que todos os indicadores de desempenho relevantes para a qualificação das ações no goalball fossem levados em consideração, com concordância consensual, em nosso sistema de observação (O’DONOGHUE, 2010; ANGUERA; MENDO, 2013). Para esse fim, dois treinadores experientes (18 anos e três anos de experiência, respectivamente; um deles com experiência de seis anos no treinamento da Seleção Brasileira de Goalball) e com vivência na arbitragem do goalball contribuíram e certificaram a validade de conteúdo da Scal-Go durante a fase de desenvolvimento do sistema (ALEXANDRE; COLUCI, 2011).

\section{Análise Estatística}

O programa IBM ${ }^{\circledR}$ SPSS para Windows (versão 20.0) foi utilizado nas análises estatísticas. Seguindo os dois objetivos do estudo, as análises dos dados foram realizadas utilizando: (i) o evento como unidade de análise (i.e. ciclo de interação situação precedenteataque-defesa), representado por cada linha de análise na sequência ad hoc da planilha (figura 1). Para isso, foi aplicado o teste qui-quadrado para descrever a frequência da ocorrência da qualidade relativa entre o desempenho de ações fortemente apropriadas às fortemente 
inapropriadas; (ii) aplicando o jogo como unidade de análise (i.e. a média/mediana dos eventos por partida), o teste $\mathrm{T}$ foi realizado para comparações entre a qualidade relativa e o nível da equipe (equipes fortes $v s$. fracas) e resultado do jogo (equipes vencedoras $v s$. perdedoras). O teste de classificação de Wilcoxon foi incorporado quando o teste de ShapiroWilk revelou casos de distribuição não paramétrica (i.e. qualidade temporal relativa à situação precedente: curta duração; ataque: qualidade relativa fortemente inapropriada e fortemente apropriada; e defesa: qualidade relativa fortemente inapropriada, inapropriada e aceitável). Distribuições não paramétricas também foram evidenciadas nos dados de resultado momentâneo (i.e. ganhando vs. empatando vs. perdendo), e por isto o teste de Friedman foi aplicado. O nível de significância foi pré-fixado em $\mathrm{p}<0,05$.

\section{RESULTADOS}

Vinte e quatro jogos de goalball resultaram em 4527 eventos - ciclos de interações entre situação precedente-ataque-defesa, sendo $189 \pm 7$ eventos computados por partida (93 \pm 4 no primeiro tempo; $95 \pm 5$ no segundo tempo); $12 \pm 4$ gols por partida ( $5 \pm 3$ no primeiro tempo; $7 \pm 3$ no segundo tempo). Setenta por cento dos primeiros gols foram realizados por equipes que venceram a partida $\left[\mathrm{X}_{2}(1)=4,17 ; \mathrm{p}<0,001\right]$. Setenta por cento dos primeiros gols foram realizados por equipes que venceram a partida $\left[\mathrm{X}_{2}(1)=4,17 ; \mathrm{p}<0,001\right]$. Além disso, 93\% e $80 \%$ dos eventos de análise com resultado momentâneo "vencendo" para o time em situação ofensiva foram compostos por equipes que venceram a partida $\left[X_{2}(2)=2714,82\right.$; $\mathrm{p}<0,001]$ e pelos times considerados fortes na competição $\left[\mathrm{X}_{2}(2)=855,39\right.$; $\left.\mathrm{p}<0,001\right]$, respectivamente.

Durante os jogos, a maioria das situações precedentes foi baseada em momentos após infração ou após ciclo regular de ataque-defesa (sem contra-ataque ou interrupção do jogo qualidade temporal relativa padrão). Todos os arremessos entre defensores ou entre defensor e trave (qualidade relativa fortemente apropriada) resultaram em gols. Contudo, $\sim 7 \%$ das situações precedentes extensas resultaram em gols, comparadas as situações padrões ( $\sim 5 \%)$ e curtas $(\sim 3 \%)\left[\mathrm{X}^{2}(2)=8.241 ; \mathrm{p}=0,016\right]$. Maior frequência de arremessos no segmento corporal central dos defensores (qualidade relativa aceitável) foi observada. No entanto, arremessos nos segmentos extremos dos defensores revelaram maior probabilidade de marcar gols [qualidade relativa apropriada, $\sim 8 \%$ de chance; $\left.X^{2}(4)=1810,14 ; p<0,001\right]$. Times em situações defensivas, estes demonstraram maior frequência de tempo de controle $\leq 1$ segundo, 
arremesso adversário para fora ou pênalti adversário (qualidade relativa fortemente apropriada) (Tabela 2.3). Importante destacar que nenhum time realizou gol contra.

Tabela 2.3. Análise da distribuição percentual dos eventos referentes à qualidade relativa nas interações situação precedente-ataque-defesa

\begin{tabular}{rccc}
\hline \multicolumn{1}{r}{ Qualidade Relativa } & Eventos (\%) & Chi-quadrado & p \\
\hline Situação precedente & & & \\
Curta & $206(4,6)$ & & $<0,001$ \\
Padrão & $3637(80,3)$ & 4577,08 & \\
Extensa & $684(15,1)$ & & \\
Ataque & & & \\
Fortemente Inapropriada & $110(2,4)$ & & \\
Inapropriado & $516(11,4)$ & & \\
Aceitável & $2597(57,4)$ & & \\
Apropriado & $1218(26,9)$ & & \\
Fortemente Apropriada & $86(1,9)$ & & \\
Defesa & & & \\
Fortemente Inapropriada & $220(4,9)$ & & \\
Inapropriado & $100(2,2)$ & & \\
Aceitável & $206(4,6)$ & & \\
Apropriado & $1383(30,6)$ & & \\
Fortemente Apropriada & $2618(57,8)$ & & \\
\hline
\end{tabular}


As relações entre as qualidades relativas e a variável contextual nível da equipe (Figura 2.2), apresentaram resultados significativos apenas na situação de defesa. Equipes fortes demonstraram maior frequência de infração (i.e. "Ball over") durante as defesas (qualidade relativa inapropriada, $\mathrm{p}=0,003$ ). Além disso, equipes fracas apresentaram mais gols sofridos (qualidade relativa fortemente inapropriada, $p=0,034$ ).

Figura 2.2. Porcentagem média das qualidades relativas entre times fortes $v s$. fracos (variável contextual: nível da equipe)

$\square$ Equipes fortes $\square$ Equipes fracas

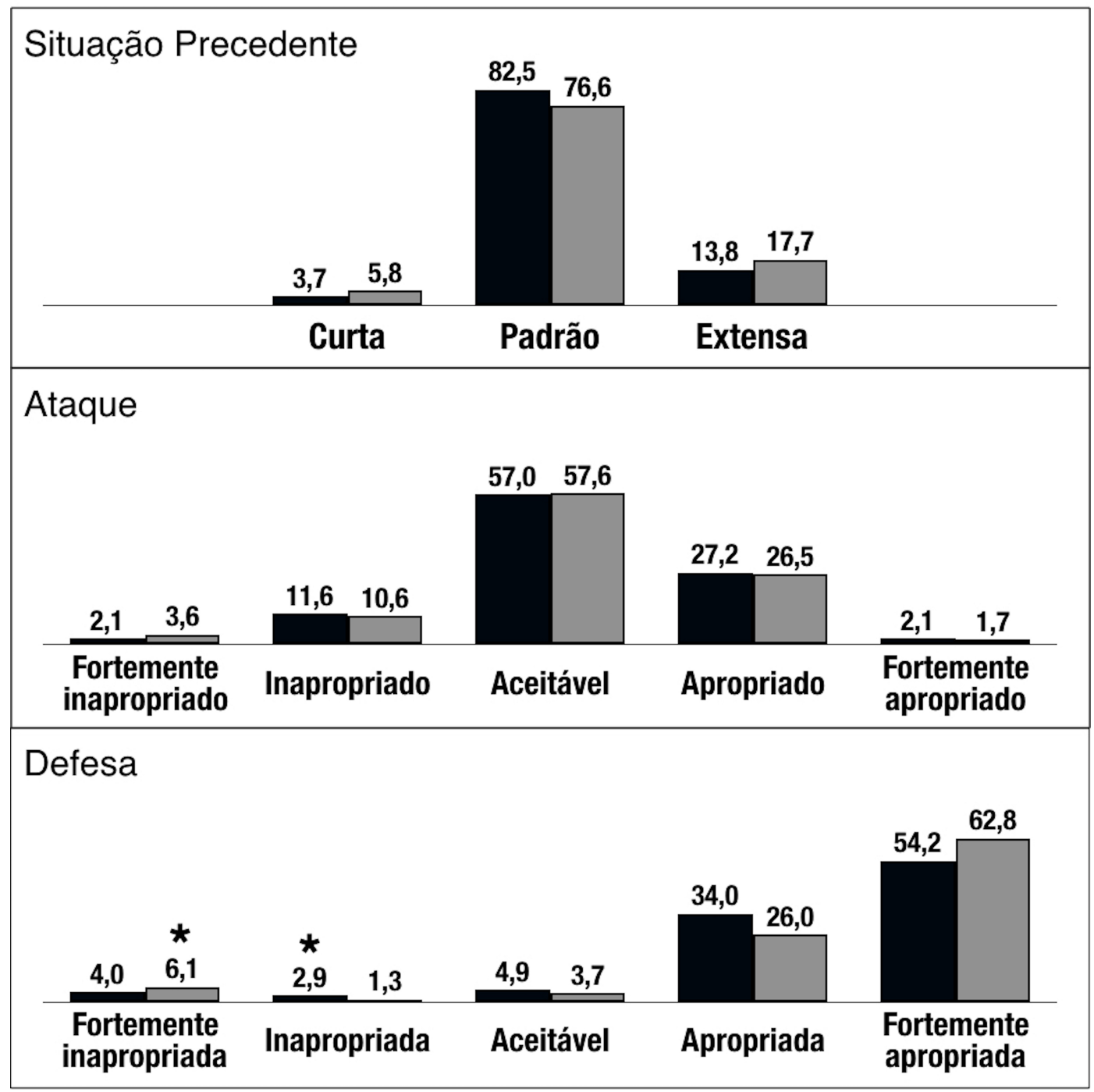

$* \mathrm{p}<0,05$. Fonte: Autoria própria 
A comparação entre as qualidades relativas e a variável contextual resultado da partida (Figura 2.3), demonstrou maior porcentagem de inícios após infração ou ciclos regulares de ataque-defesa (qualidade temporal padrão) para as equipes vencedoras $(p<0,001)$. O desempenho ofensivo dessas equipes foram superiores em arremessos ao gol entre defensores ou entre defensor e trave (qualidade relativa fortemente apropriada, $\mathrm{p}<0,001$ ). Enquanto os desempenhos defensivos evidenciaram maior incidência de infrações (i.e. "ball over", qualidade relativa inapropriada, $\mathrm{p}=0,004)$, e tempo de controle da bola de dois a três segundos (qualidade relativa apropriada, $\mathrm{p}=0,020$ ). Equipes perdedoras demonstraram maior frequência de contra-ataque (qualidade temporal curta, $p=0,024$ ) e interrupções de jogo (qualidade temporal estendida, $\mathrm{p}<0,001$ ). Ainda, equipes perdedoras apresentaram mais episódios de pênalti (qualidade relativa fortemente inapropriada, $\mathrm{p}=0,008$ ) e apresentaram maior número de gols sofridos (fortemente inapropriada, $p<0,001$ ) comparada as equipes vencedoras. 
Figura 2.3 Porcentagem média das qualidades relativas entre times vencedores vs. perdedores (variável contextual: resultado do jogo)

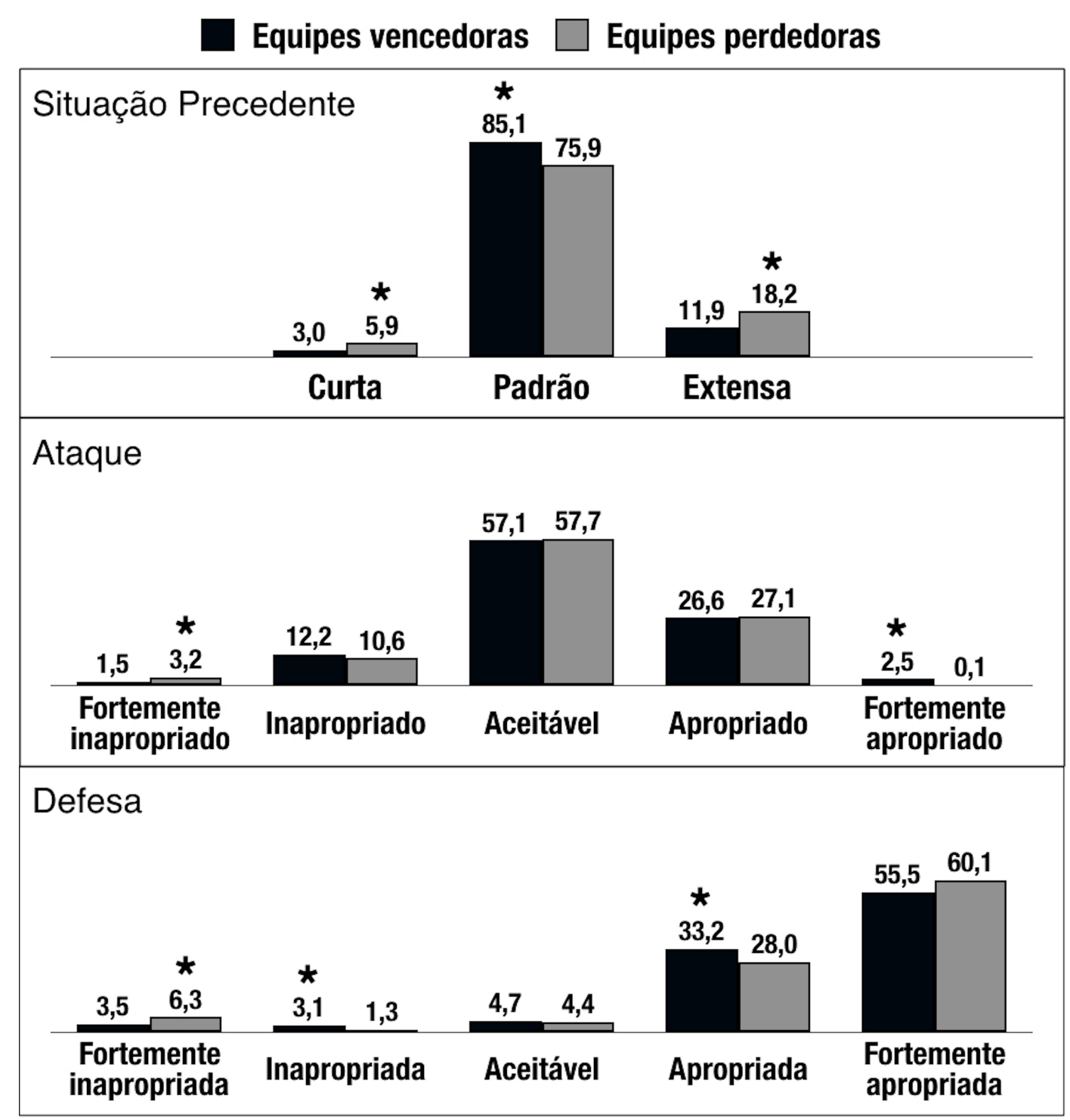

$* \mathrm{p}<0,05$. Fonte: Autoria própria. 
Observamos que o resultado momentâneo ganhando apresentou alta porcentagem de ciclo auto-organizado equilibrado (qualidade temporal padrão) comparado ao resultado empatando $(\mathrm{p}<0,001)$ e perdendo $(\mathrm{p}=0,003)$ (Figura 2.4). As fases ofensivas e defensivas sob a condição vencendo não resultaram diferenças em comparação ao estado perdendo. No entanto, o resultado momentâneo perdendo apresentou maior porcentagem de contra-ataques (qualidade temporal curta) e interrupções de jogo prévias ao ataque (qualidade temporal extensa) vs. ganhando $(\mathrm{p}<0,001)$ e empatando $(\mathrm{p}<0,001)$. Além disso, o estado perdendo apresentou maior percentual de estratégias fortemente inapropriadas $(\mathrm{p}<0,001)$, aceitáveis ( $\mathrm{p}$ $<0,002)$ e apropriadas $(\mathrm{p}<0,012)$ na fase ofensiva em comparação a situações empatando. Para defender o arremesso do adversário, o resultado momentâneo perdendo resultou em maiores tentativas de arremesso nas extremidades corporais do defensor, em comparação com o estado empatando $(\mathrm{p}<0,001)$. 
Figura 2.4. Porcentagem média das qualidades relativas entre as condições ganhando vs. empatando vs. perdendo (variável contextual: resultado momentâneo).

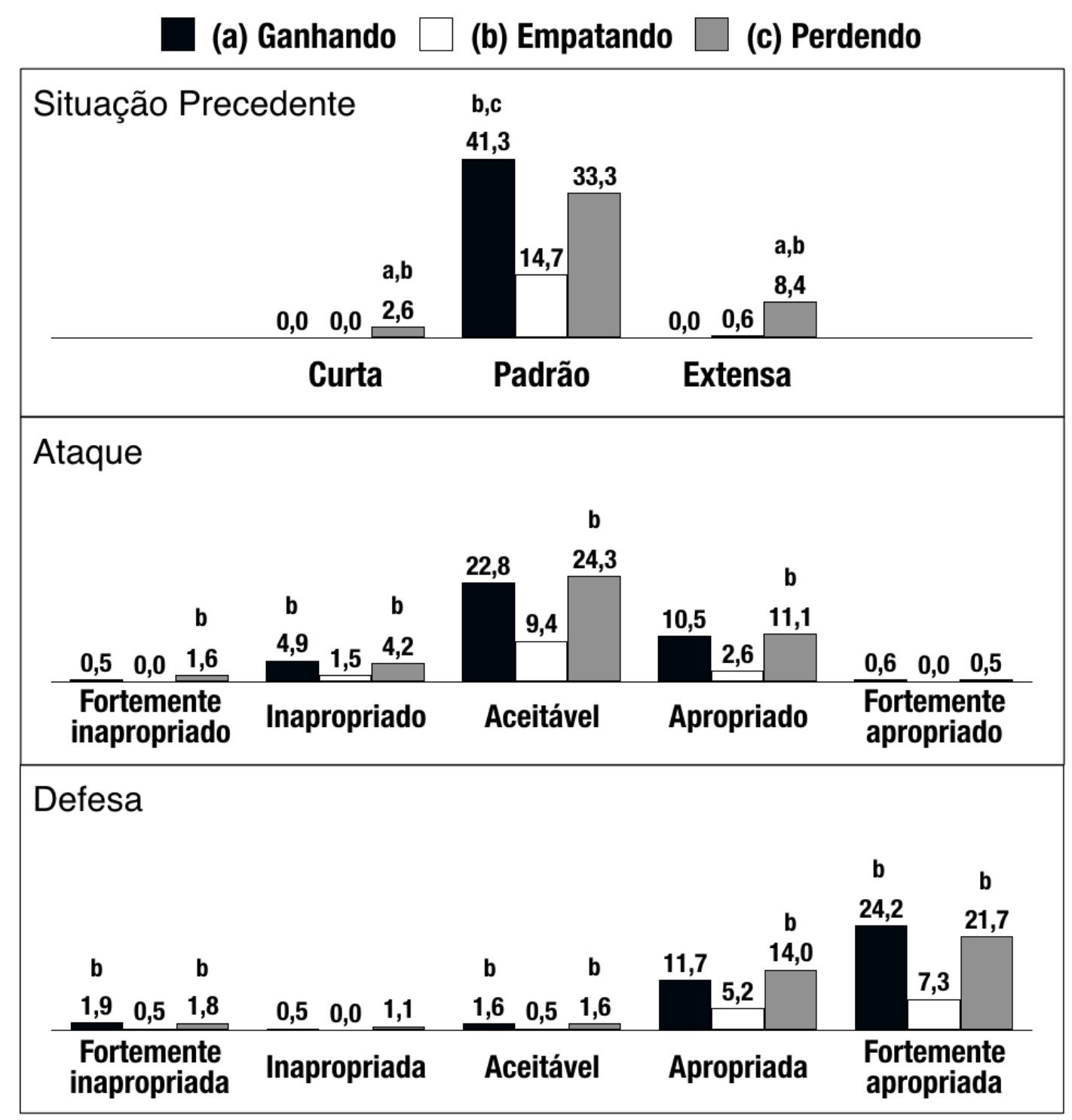

$\mathrm{a}=\mathrm{p}<0,05$ vs. ganhando; $\mathrm{b}=\mathrm{p}<0,05$ vs. empatando; $\mathrm{c}=\mathrm{p}<0,05 v s$. perdendo. Fonte: Autoria própria 


\section{DISCUSSÃO}

Este estudo é o primeiro a propor a qualificação das ações do jogo de goalball e comparar com variáveis contextuais. Nossos principais resultados mostraram uma influência significativa das variáveis contextuais no desempenho das ações, que permanecem constantemente em auto-organização, na tentativa de se tornarem fortemente apropriadas durante o jogo e a competição. Começar o jogo ganhando e permanecer nesse estado momentâneo mais tempo, tem influência positiva no resultado da partida e consequentemente, no nível da equipe. O desempenho defensivo cumpriu qualificações fortemente apropriadas entre as equipes de goalball. Para tanto, estratégias de interrupções de jogo em situações precedentes, arremessos precisos nas lacunas entre os defensores ou em suas extremidades corporais, defesas rápidas com controle da posse de bola em curto período de tempo, garantindo a todo o momento não cometer penalidade, podem levar as equipes a obterem o sucesso no goalball.

A característica tempo-dependente do goalball fornece mudanças significativas nas fases ofensiva e defensiva. Após o primeiro contato defensivo, as equipes têm dez segundos para arremessar a bola de volta à quadra adversária (IBSA, 2019); caso contrário, uma penalidade será anotada (SILVA et al., 2010). Maior desempenho das ações na fase defensiva promove extensão da situação precedente para desenvolver os princípios ofensivos. Consequentemente, os questionamento durante a tomada de decisão para preparar o ataque (quem arremessará a bola?, sob qual estratégia ofensiva? e em qual momento?) (MORATO et al., 2017) podem ser auto-organizadas para promover um ataque fortemente apropriado durante a competição ou mesmo em sessões de treinamento para aprimorar o conhecimento técnico-tático da modalidade..

Se a duração da situação precedente for curta, o arremessador interrompe rapidamente a defesa do oponente usando a estratégia de contra-ataque (MORATO et al., 2012). No entanto, $\sim 7 \%$ das situações precedentes extensas resultaram em gols. O que demonstra efeitos significativos em comparação com as situações precedentes com duração padrão $(\sim 5 \%)$ e duração curta $(\sim 3 \%)$. Nas situações de interrupção oficial, a equipe em situação ofensiva pode alterar o arremessador, a estratégia de ataque e a duração durante um período ainda maior. Além disso, a origem do arremesso pode ser alterada da referência prévia da bola, contribuindo para a redução do tempo de resposta dos defensores e, possivelmente, promovendo uma defesa menos eficaz (SILVA et al., 2010). Como as interrupções oficiais são inerentes à partida, a prática e o aprimoramento do conhecimento técnico-tático para seus 
potenciais usos após as situações de interrupções podem permitir que jogadores adquiram o entendimento de novas possibilidades de ação nesses momentos chave para a obtenção do sucesso.

Neste estudo, as equipes perdedoras e o resultado momentâneo perdendo apresentaram maior frequência de situações precedentes curtas e extensas. Isto, na tentativa de impor estratégias diferentes diante das circunstâncias desfavoráveis de jogo. Essas estratégias estão relacionadas à aceleração (i.e. contra-ataques) ou promoção da interrupção da partida na situação precedente. Por outro lado, o resultado momentâneo vencendo permitiu maior controle da pontuação da partida, fornecendo a manutenção da qualidade relativa temporal padrão. Portanto, as equipes não precisam acelerar ou interromper o ciclo do goalball. Em ciclos equilibrados e auto-organizados de defesa-ataque, as equipes vencedoras realizam ataques fortemente apropriados, encontrando a lacuna entre os defensores (LINK; WEBER, 2018). Considerando a necessidade de entender como encontrar essas lacunas, o treinamento de arremessos baseado na divisão da quadra em setores desenvolvido por Morato e colaboradores (2017), juntamente com o diálogo interno instrucional e motivacional proposto por Stamou e colaboradores (2007) em situações de cobrança de penalidade, podem fornecer um entendimento mais aprofundado sobre as estratégicas de ataque no goalball.

A fase defensiva é determinante para o sucesso (TOSIM et al., 2008). Em nosso estudo, as equipes vencedoras apresentaram mais defesas apropriadas em comparação às equipes perdedoras. Três defensores em uma ocupação racional na quadra em diferentes sistemas táticos (e.g. triângulo básico, triângulo avançado, triângulo recuado, funil, escada ou barreira, MORATO et al., 2017) propiciam um equilíbrio no balanço defensivo e na leitura da trajetória da bola coletivamente para aumentar a eficiência e eficácia defensiva (MORATO et al., 2012). Nesse contexto, o arremesso adversário para fora é considerado ideal para o time que está defendendo. Considerando as características intermitentes de alta intensidade do jogo de goalball (ALVES et al., 2018), menor gasto energético nessas situações em conjunto a uma situação precedente extensa contribui para a fase ofensiva subsequente.

O principal objetivo da fase defensiva é defender a bola (MORATO et al., 2012) e isto está diretamente relacionado ao resultado da partida (TOSIM et al., 2008). Verificamos que as equipes vencedoras, fortes e o resultado momentâneo vencendo (comparado ao estado empatando) apresentaram mais infrações defensivas (i.e. "Ball over”). Quando necessário, esses times preferem comprometer sua próxima ação ofensiva em vez de promover um desempenho aceitável, apropriado ou fortemente apropriado na fase defensiva. Um bloqueio rápido para fora ou até mesmo a infração defensiva são exemplos de estratégias relevantes na 
fase defensiva do jogo. Dessa maneira, a aplicação de jogos e atividades com constantes estímulos auditivos e movimentações prévias para a origem do arremesso adversário devem ser incluídos nos treinamentos. Uma vez que isto contribuirá para um menor tempo de reação (Silva et al., 2010) e, provavelmente, uma defesa fortemente apropriada.

Verificamos que as equipes fracas, perdedoras e o resultado momentâneo perdendo (em comparação com o estado empatando) apresentaram maior número de penalidades do que suas contrapartes. De fato, os pênaltis aumentam em $\sim 50 \%$ a probabilidade de marcar um gol em comparação com as situações de jogo efetivo (MAGALHÃES et al., 2015). Durante essa situação, a área necessária para a cobertura do gol pelo defensor é quase três vezes maior, considerando que o comprimento do corpo na posição defensiva é $~ 240 \mathrm{~cm}$ (MOLIK et al., 2015). Além disso, a referência auditiva da bola para o balanço defensivo e a leitura da trajetória do arremesso é suprimida, uma vez que a percepção sonora do adversário é, em grande parte, obtida nas situações precedentes ao arremesso.

Este estudo possui algumas limitações e possibilidades para futuras pesquisas. Consideramos a situação precedente como uma articulação entre as transições de ataque e defesa. Estudos futuros devem avaliar essas duas fases separadamente. Isto contribuirá para uma compreensão mais aprofundada sobre o comportamento anterior dos eventos de ataque e defesa. Durante a fase ofensiva, o alvo foi a única variável considerada para qualificar o desempenho das ações como aceitável, apropriado e fortemente apropriado. A origem do arremesso, o tipo, tempo, trajetória e velocidade da bola devem ser incluídas na Scal-Go, contribuindo para a qualificação ofensiva completa. Na fase defensiva, o tempo de controle da bola foi calculado desde o primeiro contato defensivo do defensor primário até o estabelecimento do controle da bola. Dessa forma, não foi contabilizado um segundo ou terceiro defensores que também contribuíram para essa defesa. O sistema tático da defesa e as interações dos jogadores podem ser fortes elementos constituintes da pontuação do desempenho das ações. Por fim, nossa amostra foi composta por partidas de goalball dos Jogos Paralímpicos Rio 2016, sob as regras internacionais até essa data. O processo de transposição de informações deve considerar os padrões de regras anteriores e atuais para as interpretações (e.g. a infração ofensiva "pass out" foi excluída das diretrizes atuais).

O jogo de goalball emerge dos padrões de movimentos ofensivos, defensivos e de suas interações com o oponente e o ambiente. Os ciclos desses eventos são influenciados pelo desempenho de suas próprias ações e por variáveis contextuais. Algumas estratégias devem ser consideradas para o treinamento de goalball: (i) o treinamento com alvos devem ser constantemente incluídos no cronograma de treino no goalball. Isto, considerando a proposta 
de atingir a lacuna entre os defensores ou locais próximos desse alvo (i.e. extremidades corporais dos defensores) para propiciar um ataque bem-sucedido; (ii) atletas de elite do goalball têm desempenho defensivo fortemente apropriado; no entanto, situações de penalidade podem influenciar negativamente esse desempenho e podem resultar em equipes perdedoras e fracas na competição. 


\section{ESTUDO 2}

\section{Reprodutibilidade e validade de um protocolo progressivo específico para a determinação da potência aeróbia máxima em jogadores de goalball}

\section{INTRODUÇÃOO}

As ações do jogo de goalball são intermitentes e caracterizam-se pela curta duração e alta intensidade. Dessa forma, constante disponibilização e restabelecimento energético são requeridos para o desenvolvimento do jogo. Até o momento, sabe-se que a contribuição do metabolismo anaeróbio lático (i.e. utilização das fontes de glicose) é ínfima comparada ao anaeróbio alático (i.e. utilização dos estoques de creatina fosfato) e aeróbio (i.e. combustão de carboidratos, gorduras e proteínas, na presença de oxigênio) (CAPUTO et al., 2009) para o desenvolvimento do jogo (ALVES et al., 2018). Em momentos específicos na partida de goalball, há subsequentes ações sem recuperação considerável que propiciam um aumento da atividade glicolítica e, portanto, um incremento significativo do processo anaeróbio lático (ALVES et al., 2018). Embora estudos tenham mostrado variações individuais atingindo concentrações lactacidêmicas aproximadas de $5 \mathrm{mM}$ durante um jogo (THEOPHILOS et al., 2005), na média, as concentrações permanecem abaixo de 3,5 mM durante e após uma partida (ALVES et al., 2018; THEOPHILOS et al., 2005), salientando que a predominância energética no goalball não é desse metabolismo.

Por outro lado, para o desempenho das ações determinantes do goalball (e.g. ataques e defesas) por um período curto de tempo (i.e. < 10 segundos), o processo anaeróbio alático se mostra determinante por modular a disponibilização energética necessária. Entretanto, as reservas de fosfocreatina degradam-se rapidamente e têm ressíntese prolongada (MEDBO; TABATA, 1989). Por isso, frequente restabelecimento dessas fontes energéticas é requerido pelo metabolismo aeróbio, que proporciona as condições basilares para a recuperação e manutenção dos esforços intermitentes no goalball (ALVES et al., 2018). Captar, transportar e utilizar o oxigênio durante o jogo é atribuído à potência aeróbia dos praticantes, a fim de restabelecer parte dos estoques de fosfocreatina muscular e manter a execução das ações e um volume maior de tempo (SPENCER et al., 2005). Durante uma partida, 56\% da disponibilização energética advêm da via aeróbia e sua taxa de utilização tem correlação inversa com a frequência de recuperações no jogo (i.e. maior potência aeróbia possibilita menor frequência de recuperações). Sabendo das diversas contribuições que a potência 
aeróbia tem para o desempenho no goalball e, ainda, que o próprio estímulo do jogo contribui para o aumento da aptidão física dos praticantes (AKINOĞLU; KOCAHAN; AKINO, 2018; CALISKAN et al., 2011; ÇOLAK et al., 2004; FURTADO et al., 2016; KARAKAYA; AKI; ERGUN, 2009; VALDÉS; GODOY; HERRERA, 2014), como avaliar o desempenho aeróbio de maneira específica em praticantes de goalball?

Protocolos progressivos até a exaustão são usualmente utilizados para a análise de variáveis fisiológicas submáximas e máximas, como é o caso da potência aeróbia máxima, a partir do incremento da intensidade (i.e. velocidade ou inclinação) em esteiras ergométricas ou ainda da potência de saída em ciclo ergômetros (BENTLEY; NEWELL; BISHOP, 2007). Embora esses procedimentos frequentemente estimem o metabolismo energético por calorimetria indireta (FERRANNINI, 1988), testes em ergômetros não preservam o princípio da especificidade quando utilizado com jogadores de goalball, tornando-se, portanto, uma medida com baixa validade ecológica (ALVES et al., 2018). Na busca por maior especificidade nesses protocolos, Gulick e Malone (2011) propuseram um teste de campo específico (modified beep test), composto por ações de ataque e defesa representativas do jogo, para avaliar a potência aeróbia em atletas de goalball. As autoras verificaram uma alta correlação $(r=0,77)$ entre o teste específico proposto e um teste incremental em cicloergômetro, avanço este que permitiu uma alternativa para os treinadores avaliarem, prescreverem e monitorarem o condicionamento aeróbio de atletas de goalball. Embora muito relevante e inovador, o estudo possui algumas limitações procedimentais. Além da não utilização do elemento estrutural "bola" durante o teste de campo, o protocolo incremental em cicloergômetro utilizado para a análise de validade do método, não é específico para os jogadores.

Como já evidenciado, a validade ecológica é fator limitante para a aplicabilidade do protocolo em contextos práticos (DAVIDS, 1988). Ainda, frente à pouca exposição de conteúdos relacionados a proposição de avaliações específicas no goalball (SIMIM et al., 2018) e considerando as possíveis adaptações de um teste físico já proposto para esta modalidade na literatura (GULICK; MALONE, 2011), o objetivo deste trabalho foi: analisar a reprodutibilidade e validade de um protocolo progressivo específico adaptado para a determinação da potência aeróbia máxima em atletas de goalball. 


\title{
MÉTODOS
}

\begin{abstract}
Amostra
O cálculo amostral foi realizado pelo software G-power (v. 3.1.9.4). Com um valor alfa admitido de 0,05 e potência estatística de $80 \%$, foram obtidas dez pessoas pelo cálculo. Dessa forma, participaram voluntariamente do presente estudo dez jogadores amadores (idade média $=40 \pm 11$ anos; massa corporal $=85,09 \pm 17,83 \mathrm{Kg}$; estatura 1,72 $\pm 0,07 \mathrm{~m}$; experiência no goalball $6 \pm 7$ anos) sem histórico de lesões músculo-esqueléticas, pertencentes à equipe masculina de goalball da Associação dos Deficientes Visuais de Ribeirão Preto e Região (ADEVIRP) e com experiências em competições de nível estadual. Todos os procedimentos foram iniciados após a aprovação do Comitê de Ética em Pesquisa para seres humanos (Escola de Educação Física e Esporte de Ribeirão Preto, Brasil - Anexo 3), e com a concordância por escrito do termo de consentimento livre e esclarecido (apresentado oralmente - Apêndice 1).
\end{abstract}

\section{Procedimentos Experimentais}

Este estudo contempla os processos de análises da reprodutibilidade e validade de um protocolo progressivo específico em quadra, denominado Fit-Go. Este, como proposta para avaliação da potência aeróbia máxima em jogadores de goalball. O Fit-Go foi baseado nas características de um protocolo progressivo em ergômetro, mas que na ocasião foi elaborado para preservar o princípio da especificidade, viabilizando sua aplicação em uma quadra. Para as análises de reprodutibilidade, o Fit-Go foi aplicado e replicado em duas situações distintas (i.e. teste e reteste) e análises da variância e de índices de reprodutibilidade de variáveis fisiológicas foram verificadas. A validade do protocolo foi testada pelo cumprimento de critérios de exaustão previamente estabelecidos e pela comparação de duas situações (i.e. reteste e esforço de verificação) sob o comportamento de variáveis fisiológicas.

\section{Desenvolvimento do Fit-Go}

A lógica da elaboração do protocolo foi fundamentada nos procedimentos que contemplam um protocolo progressivo (BENTLEY; NEWELL; BISHOP, 2007), com aquecimento e aumento progressivo da intensidade ao longo dos estágios até a exaustão. 
Considerando que o Fit-Go foi desenvolvido para jogadores de goalball (i.e. pessoas com deficiência visual) em um cenário específico (i.e. quadra esportiva), a contabilização e sinalização para os esforços dos protocolos foram constantemente realizadas por um aplicativo gratuito (Exercise Timer, Neuron Digital). Ainda, os esforços físicos envolvidos foram adaptados de estudos prévios que utilizaram ações representativas do jogo (GULICK; MALONE, 2011): 1) defesa (em posição de expectativa, ao sinal sonoro, o participante simula uma ação defensiva com deslize; 2) transição ofensiva (o participante levanta, retorna até a trave de costas, e o avaliador entrega a bola sinalizando sua localização ao encosta-la no peito do jogador); 3 ) arremesso com a bola (o jogador faz um arremesso com progressão até o limite da área de defesa), e; 4) transição defensiva (o participante retorna a posição inicial de expectativa) - veja Figura 3.1).

Figura 3.1. Sequência de ações que compõem o Fit-Go. Ação 1 (Defesa); Ação 2 (Transição ofensiva e entrega da bola pelo avaliador); Ação 3 (Arremesso com bola); e Ação 4 (Transição defensiva)

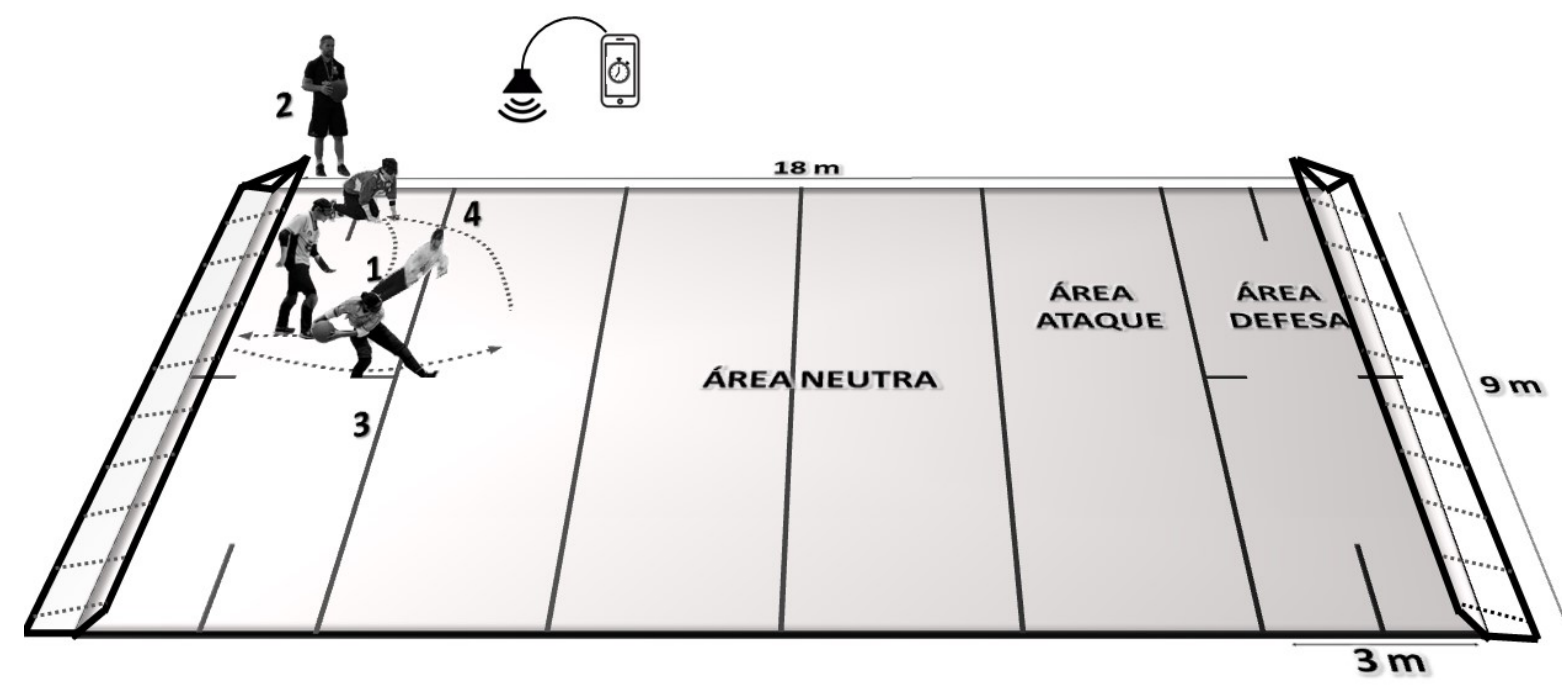

Fonte: Autoria própria

A fim de obter informações acerca do protocolo proposto, um estudo piloto $(n=2)$ foi realizado previamente e indicadores metodológicos foram destacados para posteriores ajustes no experimento: 1) Logística da coleta de dados (e.g. materiais e avaliadores necessários, área de execução do protocolo (teste, reteste e fase de verificação) e avaliação físiológica, programação dos sinais sonoros no aplicativo, entre outros); 2) Padronização dos avaliadores em suas respectivas funções (e.g. análises das variáveis fisiológicas, indicadores de carga interna e etc); 3) Implementação da bola durante o Fit-Go, e; 4) Manutenção do arremesso de 
alta qualidade (i.e. os participantes foram constantemente estimulados a desempenharem um arremesso com eficiência e eficácia de execução).

Após estas padronizações foi então elaborado o conteúdo do protocolo progressivo. Para cada estágio do protocolo, que perdurou por aproximadamente um minuto, frequências pré-estabelecidas de sequências de ações foram incorporados no Fit-Go (Tabela 3.1). A progressão da intensidade nos estágios ocorreu pelo aumento de sua densidade (i.e. incremento no número de ações para um menor tempo de execução). Dessa forma, a cada estágio foi acrescentada uma sequência de ações e diminuído em um segundo a duração dessa sequência. Os três primeiros estágios foram concebidos como períodos adaptativos, nos quais a dinâmica da realização do protocolo foi constantemente praticada. Portanto, o número de sequências foi mantido, sendo reduzida apenas a duração de sua execução. A progressão dos estágios foi realizada até a exaustão ou a incapacidade do participante em voltar para a primeira ação da sequência por pelo menos três vezes consecutivas.

Tabela 3.1. Caracterização procedimental do protocolo progressivo Fit-Go.

\begin{tabular}{|c|c|c|c|}
\hline \multirow[b]{2}{*}{ Estágios } & \multirow{2}{*}{$\begin{array}{c}\text { Frequências das } \\
\text { sequências }\end{array}$} & \multicolumn{2}{|c|}{ Duração (segundos) } \\
\hline & & Sequências & Estágios \\
\hline \multicolumn{4}{|c|}{ Adaptação } \\
\hline 1 & 4 & 15 & 60 \\
\hline 2 & 4 & 14 & 56 \\
\hline 3 & 4 & 13 & 52 \\
\hline \multicolumn{4}{|c|}{ Progressão } \\
\hline 4 & 5 & 12 & 60 \\
\hline 5 & 6 & 11 & 66 \\
\hline 6 & 7 & 10 & 70 \\
\hline 7 & 8 & 9 & 72 \\
\hline 8 & 9 & 8 & 72 \\
\hline 9 & 10 & 7 & 70 \\
\hline 10 & 11 & 6 & 66 \\
\hline $\mathrm{n}+1$ & $\mathrm{n}+1$ & $n-1$ & $\mathrm{~F}^{*} \mathrm{~S}$ \\
\hline
\end{tabular}

Nota: o número de estágios variou de acordo com o desempenho dos participantes, portanto: $\mathrm{n}=$ número anterior da mesma coluna; $\mathrm{F}^{*} \mathrm{~S}=$ multiplicação entre a frequência e o tempo das sequências no mesmo estágio.

\section{Reprodutibilidade e Validade}

O experimento foi realizado no ginásio esportivo da ADEVIRP como forma de padronizar as adaptações e facilidades de acesso já concebidas pelos jogadores de goalball. Além dos estímulos de familiarização, realizados em momentos distintos dentro do ciclo de 
treinamento da equipe, para as análises de reprodutibilidade e validade, o Fit-Go foi aplicado em três situações distintas: teste (protocolo Fit-Go), reteste (protocolo Fit-Go) e esforço de verificação (esforço máximo na intensidade correspondente ao último estágio alcançado na situação teste) (NOLAN; BEAVEN; DALLECK, 2014). Vale destacar que, os estágios finais incompletos na situação teste, foram considerados para o esforço de verificação, apenas quando o número de sequências realizadas excedeu $50 \%$ da frequência pré-determinada. A situação reteste foi aplicada 72 e 96 horas após o teste para três e sete participantes, respectivamente. O esforço de verificação foi realizado no mesmo dia do reteste para nove atletas (i.e. 30 minutos após recuperação do último esforço). Para o décimo atleta, a fase de verificação foi aplicada 96 horas após o reteste, devido a uma falha técnica na configuração da sinalização dos esforços pelo aplicativo utilizado.

A reprodutibilidade do Fit-Go foi verificada pela: a) análise da variância de quatro variáveis fisiológicas [i.e., consumo de oxigênio $\left(\mathrm{VO}_{2}\right)$ em repouso $\left(\mathrm{VO}_{2 \mathrm{BASAL}}\right)$ e após o exercício $\left(\mathrm{VO}_{2 \mathrm{PICO}}\right)$; concentrações sanguíneas de lactato ([Lac $]$ ) em repouso ([Lac $]_{\mathrm{BASAL}}$ ) e após o exercício ([Lac] $]_{\mathrm{PICO}}$ ); frequência cardíaca $(\mathrm{FC})$ em repouso $\left(\mathrm{FC}_{\mathrm{BASAL}}\right)$, durante os estágios e após o exercício (FC $\mathrm{FÁx}_{\mathrm{x}}$ ) e, percepção subjetiva do esforço (PSE) durante os estágios e após o exercício]; e b) pela verificação de três índices de reprodutibilidade [i.e. coeficiente de correlação intraclasse (CCI); erro típico (ET); e, coeficiente de variação $(\mathrm{CV} \%)]$. A validade foi testada pelo cumprimento de critérios de exaustão previamente estabelecidos: coeficiente respiratório $(\mathrm{QR}>1,0)$; $\mathrm{FC}_{\mathrm{MÁX}}>95 \%$ da predita para idade; $[\mathrm{Lac}]_{\mathrm{PICO}}>$ 8,0 mM; PSE score 10 (EDVARDSEN; HEM; ANDERSSEN, 2014); VO

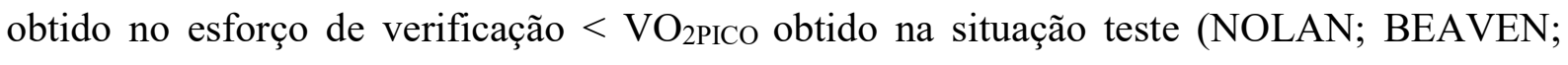
DALLECK, 2014); pela efetividade do protocolo (i.e. indivíduos que cumpriram três ou mais critérios de exaustão); e pela análise comparativa de quatro variáveis fisiológicas (i.e. $\mathrm{VO}_{2 \mathrm{PICO}}, \mathrm{FC}_{\mathrm{MÁx}},[\mathrm{Lac}]_{\mathrm{PICO}}$ e PSE). Veja o desenho experimental na Figura 3.2.

\section{Instrumentação}

As análises do $\mathrm{VO}_{2 \mathrm{BASAL}} \mathrm{e} \mathrm{VO}_{2 \mathrm{PICO}}$ foram realizadas por calorimetria indireta (FERRANNINI, 1988) utilizando-se da técnica de retro extrapolação quando necessária (ALVES et al., 2018; CAMPOS et al., 2017; CHAVERRI et al., 2016; LÉGER; SELIGER; BRASSARD, 1980; RODRIGUEZ et al., 2017) por meio dos analisadores de gases metabólicos Quark e K4b2 (Cosmed, Roma, Itália), calibrados seguindo as diretrizes do fabricante antes do início das avaliações. A utilização destes dois analisadores de gases foi 
necessária para o cumprimento das avaliações no período pré-determinado. Ainda, quando comparados para um mesmo protocolo aplicado em dias diferentes, ambos os equipamentos apresentam variações dentro do limite de concordância (EISENMANN et al., 2003). Em repouso, a linha de amostra do analisador de gases foi acoplada ao participante e o $\mathrm{VO}_{2 \mathrm{BASAL}}$ foi assumido como a média dos valores de $\mathrm{VO}_{2}$ durante um minuto. Enquanto que para a análise após o exercício, utilizando-se da técnica de retro extrapolação, foi possibilitado ao participante desempenhar o protocolo progressivo sem o acoplamento da máscara do ventilômetro (LÉGER; SELIGER; BRASSARD, 1980). Dessa forma, imediatamente após a exaustão no teste ( 3 segundos) o participante foi fixado à linha de amostra, instruído a respirar normalmente e permanecer estático em uma cadeira ao lado do local de avaliação (Figura 3.3). Os valores de $\mathrm{VO}_{2}$ dos primeiros 30 segundos de recuperação foram transformados em log e plotados linearmente em função do tempo. Com a adição da linha de tendência no gráfico, o valor do intercepto-y da equação da reta, após reversão dos valores do logaritmo, foi considerado o $\mathrm{VO}_{2 \mathrm{PICO}}$ (CAMPOS et al., 2017).

Figura 3.2. Desenho experimental

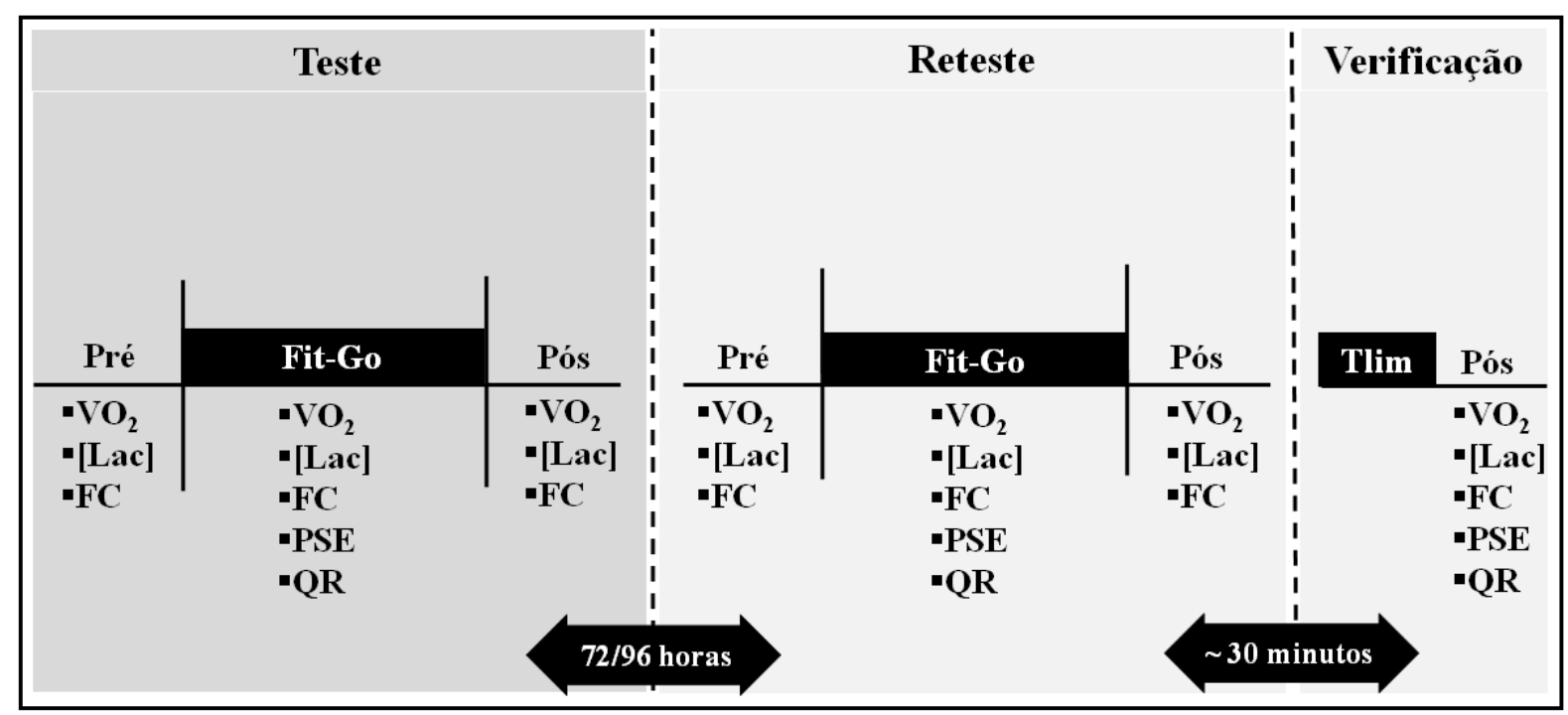

$\mathrm{VO}_{2}$ : consumo de oxigênio; [Lac]: Concentrações sanguíneas de lactato; FC: Frequência cardíaca; PSE: percepção subjetiva de esforço; QR: coeficiente respiratório, e;Tlim: tempo limite em um esforço máximo na intensidade correspondente ao último estágio obtido no Fit-Go na situação teste (Dia 1). Fonte: Autoria própria. 
Figura 3.3. Representação do protocolo Fit-Go com as respectivas funções dos avaliadores.

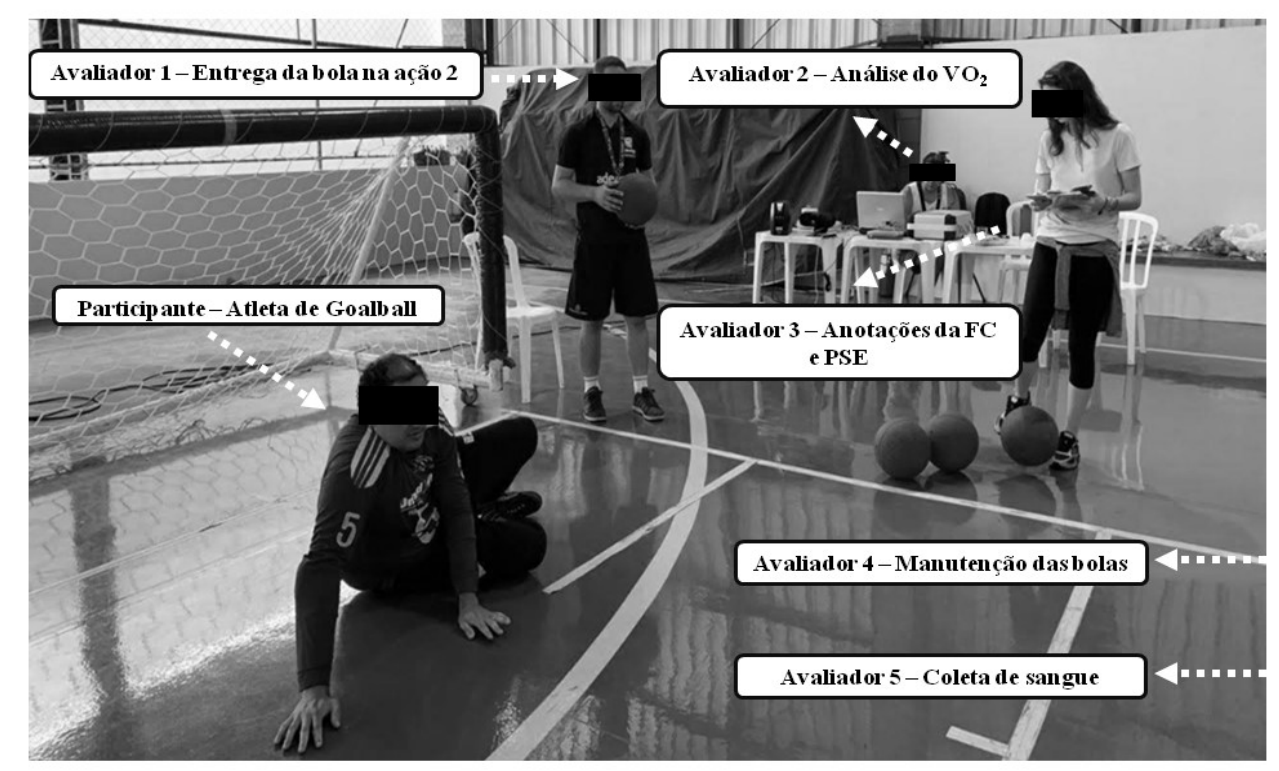

Fonte: Autoria própria

As análises dos batimentos cardíacos pela FC foram verificadas por monitor cardíaco (POLAR) com imputação instantânea dos dados por aplicativo gratuito (Elite HRV). A PSE foi apresentada e adquirida verbalmente pela escala CR-10 de Borg (1982) adaptada por Foster (2001). Para padronização da obtenção da medida (BURGESS, 2017), familiarizações foram realizadas com os participantes previamente ao experimento e um mesmo avaliador pronunciou a escala em todas as situações realizadas (i.e. teste, reteste e esforço de verificação). Os valores de QR também foram verificados pelo analisador de gases. A taxa de utilização dos carboidratos e lipídios foi quantificada durante os primeiros 30 segundos de recuperação após a exaustão e obtida pela razão entre o volume de dióxido de carbono produzido e o volume de oxigênio consumido (i.e. $\mathrm{VCO}_{2} / \mathrm{VO}_{2}$ ) (JEUKENDRUP; WALLIS, 2005).

Para as análises das [Lac] foram obtidas amostras de $25 \mu \mathrm{L}$ de sangue do lóbulo da orelha por meio de lancetas e coletas por capilares calibrados. O sangue coletado foi depositado em tubos eppendorf com $50 \mu \mathrm{L}$ de fluoreto de sódio (concentração de 1\%). As amostras foram congeladas a $-12^{\circ} \mathrm{C}$ para análise em equipamento específico (Lactímetro YSI2300, Yellow Springs Instruments ${ }^{\circledR}$, Ohio, EUA). Após a obtenção dos dados lactacidêmicos foram necessárias duas correções: a) considerando a solução total combinada de sangue e fluoreto no tubo eppendorf (i.e. $75 \mu \mathrm{L}$ ) e o conteúdo extraído pelo lactímetro para a análise 
(i.e. $5 \mu \mathrm{L}$ ), o valor analisado no lactímetro foi reparado para a sua proporção real (i.e. proporção real $=33^{*}$ valor analisado); e, b) baseado no valor obtido para uma solução padronizada de [Lac] (e.g. 5,02mM) e seu valor esperado (i.e.5mM), a proporção real do [Lac] foi novamente corrigida $\left\{\right.$ e.g., $\left(5^{*}\right.$ proporção real $\left.) / 5,02=[\mathrm{Lac}]\right\}$. A $[\mathrm{Lac}]_{\mathrm{BASAL}}$ foi definida com os cálculos acima mencionados. Para a análise do [Lac]PICO, além das duas correções, foi verificado o maior valor de [Lac] entre o $3^{\circ}, 5^{\circ}$ e $7^{\circ}$ minuto após a exaustão do participante.

\section{Análise estatística}

A normalidade dos dados foi testada e confirmada pelo teste de Shapiro-Wilk. A comparação entre os protocolos de Fit-Go nas situações teste e reteste foi realizada por meio de uma análise de variância para modelos mistos contendo fatores fixos (situação e estágio) e randômicos (sujeito). Esta análise foi seguida pelo teste Pos-Hoc de Sidak, quando necessário. A reprodutibilidade do Fit-Go foi testada pelos índices CCI [0,90-1,00= excelente; 0,80-0,89 = boa; 0,60-0,79 = regular; < 0,59 = fraca, GINANNICHI (1984)], ET e CV\%, (HOPKINS, 2000). O cumprimento dos critérios nas situações teste e reteste foram verificados por meio do teste Qui-quadrado. Entretanto, em todos os casos a frequência esperada de pelo menos uma das casas foi menor do que cinco observações. Assim estas análises foram interpretadas pelo teste de Fisher. Por fim, as respostas do Fit-Go da situação reteste foram comparadas aos valores do esforço de verificação por meio do teste $t$ de student para amostras dependentes. Todas as análises foram realizadas no software SPSS versão 20.0 (IBM Corp, NY, USA), adotando-se um nível de significância de $\mathrm{p}<0,05$.

\section{RESULTADOS 5}

\section{Reprodutibilidade}

A Figura 3.4 apresenta as respostas fisiológicas durante as situações teste e reteste, para as comparações no domínio do tempo (valores de repouso e valores na exaustão), situação e interação (teste e reteste). $\mathrm{O} \mathrm{VO}_{2}$ demonstrou efeitos significativos do tempo (F =

\footnotetext{
${ }^{5}$ Todos os participantes receberam um relatório resumido em áudio com os principais resultados e possíveis implicações práticas para seu desempenho no treinamento.
} 
$167,8 ; \mathrm{p}<0,01)$, mas nenhum efeito significativo das situações $(\mathrm{F}=1,02 ; \mathrm{p}=0,33)$ ou interações $(F=0,48 ; p=0,49)$. Resultados semelhantes foram observados para a $F C$, a qual apresentou efeitos do tempo $(F=26,2 ; p=0,001)$, mas não da situação $(F=1,67 ; p=0,20)$ ou interação $(F=0,38 ; p=0,88)$. A PSE apresentou efeitos significativos do tempo $(F=41,6 ; p=$ $0,01)$ e da situação $(F=5,62 ; p=0,02)$, mas sem interações significativas $(F=0,84 ; 0,53)$, o que indica variações similares entre o teste e reteste. As [Lac] demonstraram efeitos significativos do tempo $(F=252,8 ; p=0,001)$, da situação $(F=7,18 ; p=0,015)$ e também uma interação significativa $(F=7,96 ; p=0,011)$, o que demonstra que as concentrações deste metabólito foram dependentes da situação (i.e. valores superiores na situação teste).

A Tabela 3.2 apresenta os valores obtidos para os índices de reprodutibilidade. Nível bom de precisão da medida foi obtido para o CCI da PSE $(\mathrm{CCI}=0,84)$, regular para $\mathrm{VO}_{2}$ $(\mathrm{CCI}=0,71)$ e $[\mathrm{Lac}](\mathrm{CCI}=0,64)$ e fraco para FC $(\mathrm{CCI}=0,52)$. Baixos erros típicos acompanhados de valores dentro do esperado para o CV\% (i.e. $\sim 10 \%$ ) (ATKINSON; NEVILL, 1998) foram demonstrados para todas as variáveis analisadas.

Figura 3.4. Valores médios e desvio padrão do consumo de oxigênio $\left(\mathrm{VO}_{2}\right)$ e concentrações sanguíneas de lactato ([Lac]) em repouso e após o exercício; frequência cardíaca (FC) e percepção subjetiva de esforço (PSE) em repouso, durante os estágios e após o exercício.
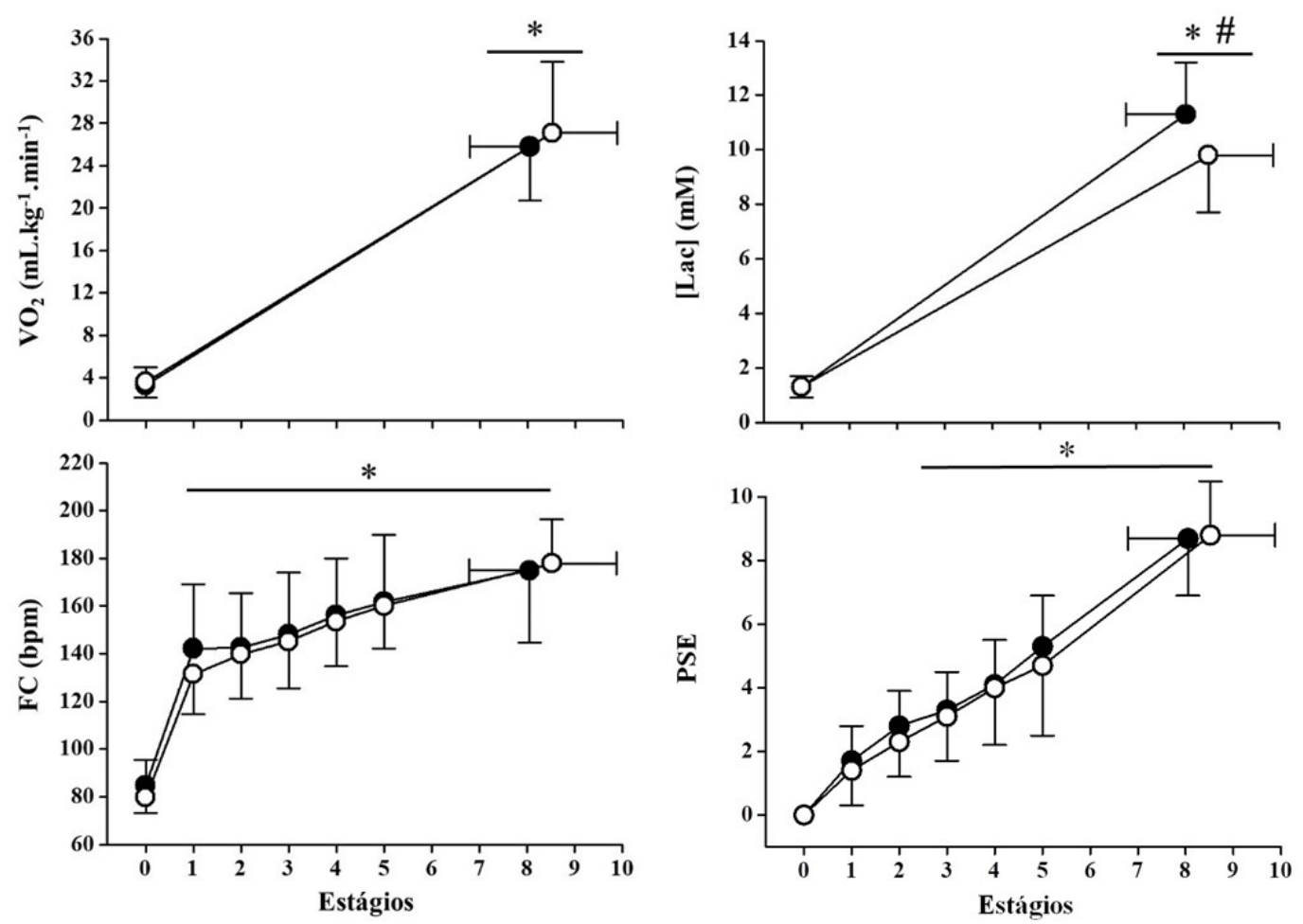

Símbolos fechados: teste; Símbolos abertos: reteste; * Efeitos significativos do tempo em relação aos valores de repouso $(p<0,05)$; \# Efeitos do tempo e da situação com interação significativa $(p<0,05)$. Fonte: Autoria própria 
Tabela 3.2. Índices de reprodutibilidade das variáveis observadas nas situações teste e reteste.

\begin{tabular}{cccc}
\hline & CCI & ET & CV\% \\
\hline VO$_{2}$ (mL.Kg $\left.{ }^{1-} \cdot \mathbf{m i n}^{-1}\right)$ & $0,71^{*}$ & 3,2 & 12,4 \\
FC (bpm) & $0,52^{*}$ & 17,3 & 9,9 \\
PSE (u.a.) & $0,84^{*}$ & 0,7 & 7,9 \\
[Lac] (mM) & $0,64^{*}$ & 1,2 & 11,7 \\
\hline
\end{tabular}

ICC: Coeficiente de correlação intraclasse; ET: Erro típico; $\mathrm{CV} \%$ : Coeficiente de variação; $\mathrm{VO}_{2}$ : Consumo de oxigênio; FC: Frequência cardíaca; PSE: Percepção subjetiva de esforço; [Lac]: Concentrações sanguíneas de lactato. ${ }^{*}=\mathrm{p}<0,05$.

\section{Validade}

A Tabela 3.3 demonstra as frequências observadas do cumprimento dos diferentes critérios para a determinação do $\mathrm{VO}_{2 \text { PICO }} \mathrm{O}$ teste qui-quadrado não demonstrou associação entre a situação e o cumprimento dos diferentes critérios. Inclusive o critério de efetividade do Fit-Go (i.e. participantes que cumpriram três ou mais critérios), não foi associado entre as situações.

A Figura 3.5 demonstra as comparações realizadas entre o teste incremental da situação reteste e o esforço de verificação realizado em $\sim 30$ minutos após recuperação. Apenas os valores de $\mathrm{VO}_{2 \mathrm{PICO}} \mathrm{e} Q \mathrm{Q}$ foram significativamente diferentes $(\mathrm{p}<0,03)$. Para o $\mathrm{VO}_{2 \text { PICO }}$ apenas dois participantes aumentaram seus valores durante a fase de verificação (+ $0,25 \mathrm{e}+3,43 \mathrm{~mL} \cdot \mathrm{kg}^{-1} \cdot \mathrm{min}^{-1}$, respectivamente). Dos participantes que não atingiram o critério do QR (quatro pessoas), dois aumentaram seus valores após o esforço de verificação. As [Lac] foram inferiores a $8 \mathrm{mM}$ apenas para um participante, o que se manteve após o esforço de verificação. Resultados semelhantes foram observados para a FC (dois participantes). A PSE do esforço de verificação foi obtida apenas para 50\% dos participantes, impossibilitando as comparações com a situação reteste.

Importante destacar que para todos os resultados obtidos foi descartada a possibilidade de efeitos de aprendizagem (CAVAZOTTO et al., 2014; WATT; HOPKINS; SNOW, 2002). Além da experiência prática dos participantes com o goalball e, portanto, compreensão total das habilidades motoras exigidas no jogo e no Fit-Go, o processo de familiarização ao protocolo foi implementado previamente ao desenvolvimento deste experimento. Para tanto, os resultados acima apresentados foram decorrentes do estímulo ao teste e não pela adaptação (aprendizagem) ao mesmo. 
Tabela 3.3. Frequências observadas (esperadas) dos participantes que cumpriram (Positivo) ou não (Negativo) os critérios para determinação do consumo pico de oxigênio nas situações teste e reteste.

\begin{tabular}{ccccccc}
\hline & \multicolumn{2}{c}{ Teste } & & \multicolumn{2}{c}{ Reteste } & \multirow{2}{*}{ p } \\
\cline { 2 - 3 } \cline { 5 - 6 } \cline { 5 - 6 } & Positivo & Negativo & & Positivo & Negativo & \\
\hline 90\% da FCMíx & $8(8,0)$ & $2(2,0)$ & & $8(8,0)$ & $2(2,0)$ & 1,00 \\
PSE score 10 & $5(5,0)$ & $5(5,0)$ & & $5(5,0)$ & $5(5,0)$ & 1,00 \\
{$[$ Lac] $>$ 8mM } & $10(9,5)$ & $0(0,5)$ & & $9(9,5)$ & $1(0,5)$ & 0,99 \\
QR $>\mathbf{1 , 0}$ & $7(6,5)$ & $3(3,5)$ & & $6(6,5)$ & $4(3,5)$ & 0,99 \\
Verificação & $8(7,5)$ & $2(2,5)$ & & $8(7,5)$ & $2(2,5)$ & 1,00 \\
Efetividade & $10(9,5)$ & $0(0,5)$ & & $8(9,0)$ & $2(0,5)$ & 0,47 \\
\hline
\end{tabular}

QR: coeficiente respiratório $(>1,0)$; FC: Frequência cardíaca ( $>95 \%$ da $\mathrm{FC}_{\mathrm{MÁx}}$ predita para idade); [Lac]: Concentrações sanguíneas de lactato $(>8,0 \mathrm{mM})$; PSE: Percepção subjetiva de esforço (score $10)$; Verificação $\left(\mathrm{VO}_{2 \mathrm{PICO}}\right.$ obtido no esforço de verificação $<\mathrm{VO}_{2 \mathrm{PICO}}$ obtido na situação teste); Efetividade: funcionalidade do protocolo em determinar o consumo pico de oxigênio (indivíduos que cumpriram três ou mais critérios).

Figura 3.5. Valores médios e desvio padrão observados ao final da situação reteste (símbolos vazios a esquerda) e após a exaustão no esforço de verificação (símbolos vazios a direita).
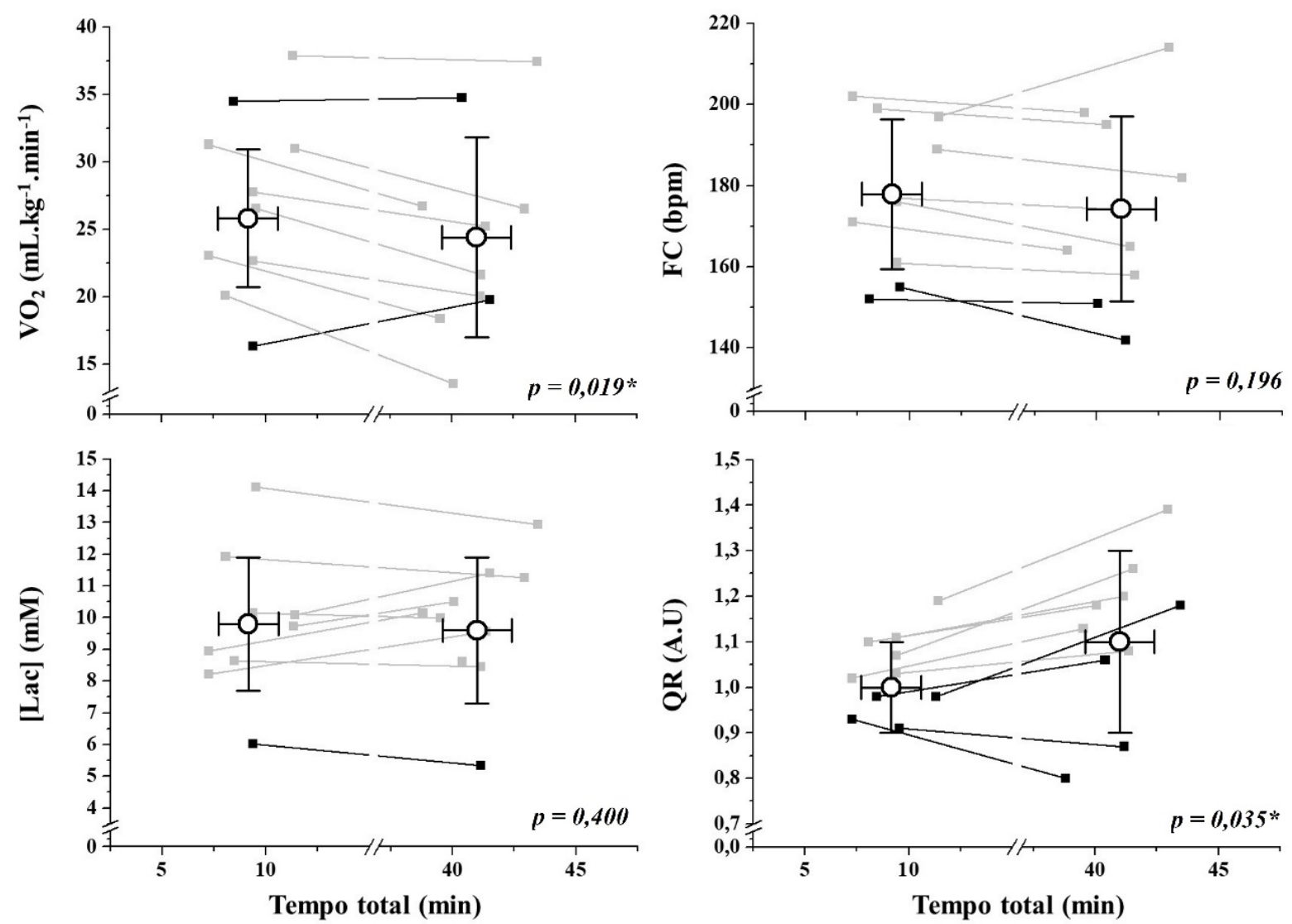

Símbolos em cinza claro representam os valores apresentados pelos participantes que cumpriram os respectivos critérios para a determinação do $\mathrm{VO}_{2 \text { PICO }}$ e os símbolos em preto representam aqueles que não cumpriram os critérios. Fonte: Autoria própria 


\section{DISCUSSÃO}

O objetivo do presente estudo foi analisar a reprodutibilidade e validade de um protocolo progressivo específico para a determinação da potência aeróbia máxima em jogadores de goalball. Nossos resultados confirmaram a reprodutibilidade nas situações teste e reteste do Fit-Go assumindo que: (i) as análises de variância do $\mathrm{VO}_{2}$ e $\mathrm{FC}$ não apresentaram efeitos da situação; e (ii) a PSE obteve variações similares e bons índices de reprodutibilidade. $\mathrm{O}$ valor do $\mathrm{VO}_{2 \mathrm{PICO}}$ obtido na situação reteste não foi confirmado no esforço de verificação. Contudo, a efetividade do Fit-Go no cumprimento de três ou mais critérios de exaustão em $100 \%$ e $80 \%$ dos participantes na situação teste e reteste, respectivamente, confirmaram a funcionalidade do protocolo na determinação da potência aeróbia máxima de jogadores de goalball. Além disso, o Fit-Go se mostrou válido para as análises de dois índices máximos (i.e. $\mathrm{FC}_{\mathrm{MÁX}}$ e [Lac] $]_{\mathrm{PICO}}$ ), uma vez que essas variáveis não apresentaram diferenças para ambas as situações de validação (i.e. reteste e esforço de verificação). Os resultados acima expostos asseguram a utilização do Fit-Go como um protocolo progressivo específico para a determinação da potência aeróbia de jogadores de goalball.

Devido à alta incidência de inatividade física entre pessoas com deficiência visual (LIEBERMAN; MCHUGH, 2001), publicações direcionadas as proposições de testes físicos relacionados à saúde são expressivos na área do goalball. Análises do controle postural são os mais aplicados a esse paradesporto (AKINOGLU; KOCAHAN, 2018; AYDOĞ et al., 2006; BEDNARCZUK et al., 2017; ÇOLAK et al., 2004; NOGUEIRA; SHIBATA; GAGLIARDI, 2009; SANTOS et al., 2018). Força, resistência, mobilidade de membros superiores, inferiores e flexibilidade também são condições ocasionalmente investigadas (ÇOLAK et al., 2004; FURTADO et al., 2016; KARAKAYA; AKI; ERGUN, 2009). Com a aplicação de testes laboratoriais e de campo (e.g. Brockport Physical Fitness Test, teste de preensão manual, YoYo intermittent recovery test level 1 , teste de velocidade da bola e modified beep test) (FURTADO et al., 2016; GOULART-SIQUEIRA et al., 2018; GULICK; MALONE, 2011) o aprimoramento da aptidão física com a prática do goalball foi constatado e se mostra uma literatura bem estabelecida no goalball. Entretanto, para um melhor desempenho esportivo, as proposições de testes físicos reprodutíveis, válidos, específicos e aplicáveis em contextos práticos são pontos chave no processo de avaliação, prescrição e monitoramento das equipes de goalball.

Consistência e precisão operacional e temporal foram obtidas no Fit-Go para as variáveis $\mathrm{VO}_{2}$, FC e PSE (ATKINSON; NEVILL, 1998). Considerando que a obtenção da 
reprodutibilidade de testes de campo são usualmente desenvolvidos e validados para a aplicação no contexto prático, os resultados obtidos no presente estudo detém uma significância prática do procedimento (MORROW; JACKSON, 1993). Adaptado da proposta de Gulick e Malone (2011), o Fit-Go foi bem sucedido como um teste incremental até a exaustão baseado em esforços específicos da fase ofensiva e defensiva do goalball (MORATO; GOMES; ALMEIDA, 2012). Adicionalmente, este foi o primeiro estudo a aplicar análises da reprodutibilidade em conjunto à validade do protocolo proposto com jogadores desta modalidade. Por isso, apontamentos procedimentais específicos deste experimento são necessários para o entendimento dos resultados obtidos.

A análise do consumo de oxigênio para a determinação da potência aeróbia foi diferente dos procedimentos anteriormente aplicados com praticantes de goalball. A calorimetria indireta com o diagnóstico do ar inspirado e expirado de forma ininterrupta em teste laboratorial (ALVES et al., 2018; GULICK; MALONE, 2011) foi ocasionalmente alterada para um procedimento válido sem o acoplamento constante da máscara do analisador de gases: a técnica de retro extrapolação (LÉGER; SELIGER; BRASSARD, 1980). Baseada em experiências prévias com jogadores de goalball, esse procedimento potencializa a especificidade do protocolo quando aplicada em ambiente esportivo, principalmente por reduzir os constrangimentos impostos pelo uso do equipamento durante o exercício (ALVES et al., 2018; CAMPOS et al., 2017; CHAVERRI et al., 2016). Os resultados oriundos da reprodutibilidade do $\mathrm{VO}_{2}$ no Fit-Go confirmam a capacidade de reproduzir esta variável sob esta nova perspectiva de avaliação em contexto paradesportivo.

Contudo, avaliações do consumo de oxigênio apresentam alto custo de aplicação, principalmente pelo uso de um analisador de gases. Portanto, os resultados obtidos para a FC (i.e. sem efeito da situação e interação entre o teste e reteste) e PSE (i.e. com efeito da situação, mas com variância similar; e bons índices de reprodutibilidade) indicam uma solução prática, de baixo custo e reprodutível para a avaliação no goalball. Ainda, esses indicadores favorecem o estabelecimento de âncoras fisiológicas para a prescrição e monitoramento do treinamento. Por exemplo, 50\%, 60\%, 70\%, 80\%, 90\% e $100 \%$ da $\mathrm{FC}_{\mathrm{MÁx}}$ $=28 \%, 40 \%, 58 \%, 70 \%, 83 \%$ e 100\% do $\mathrm{VO}_{2 \mathrm{MÁX}}$, respectivamente (MCARDLE, 2016, p. 719), exercícios de baixa intensidade (i.e. zona 1: PSE score $\leq 4)$, média intensidade (i.e. zona 2: $4<$ PSE score $<7$ ) e alta intensidade (i.e. zona 3: $\geq$ PSE score 7) (SEILER; KJERLAND, 2006) e consequentemente aumentam o poder de difusão em ambientes esportivos (BURGESS, 2017). As [Lac] não foram reprodutíveis e seus resultados apresentaram dependência da situação de avaliação. Considerando que as análises desse metabólico podem 
ser influenciadas pelo estado nutricional e variabilidade de idade, acreditamos que a ausência do controle alimentar e a heterogeneidade dos participantes podem ter interferido na interpretação dos resultados (JACOBS, 1986). Mesmo que instruções quanto a manutenção do conteúdo e frequência alimentar e de treinamento tenham sido enfatizadas aos participantes previamente ao experimento.

O Fit-Go se mostrou efetivo no cumprimento de três ou mais critérios mínimos de exaustão em $100 \%$ e $80 \%$ dos participantes na situação teste e reteste, respectivamente. Ainda, o preenchimento de todos os critérios não foi associado à situação de avaliação. Independentemente do momento em que o protocolo foi aplicado, os critérios referentes a

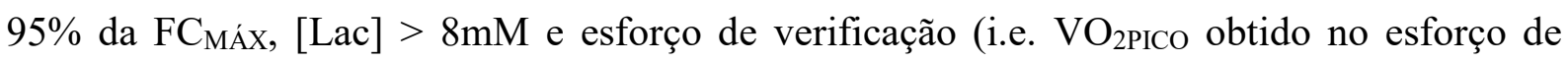

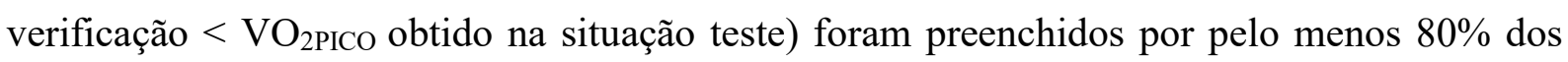
participantes nas situações teste e reteste. Os resultados para QR $>1,0$ e PSE score 10 foram contempladas por uma menor porcentagem de participantes (i.e. $50 \%$ a $70 \%$ dos participantes). Acreditamos que a ausência no controle nutricional para $\mathrm{o} Q \mathrm{QR}$ (JEUKENDRUP; WALLIS, 2005) e a necessidade de mais familiarizações com a PSE (i.e. inclusão desse método na rotina de treinamento) (FOSTER et al., 2001) são necessárias em futuras pesquisas que pretendam utilizar essas variáveis como critérios de exaustão. As análises da [Lac] como critério se mostraram mais eficazes entre todas as variáveis verificadas. De fato, as análises desse metabólito são amplamente utilizadas na literatura como marcador fisiológico de intensidade (CAPUTO et al., 2009) e os resultados aqui presentes comprovam o incremento da intensidade proporcionado pelo aumento da densidade no conteúdo de atividades do Fit-Go.

A medida direta do consumo de oxigênio por amostras do ar expirado em equipamento específico, em um teste de esforço máximo em contexto laboratorial é confiável e válida ("padrão ouro") para a determinação da potência aeróbia (ACSM, 2014, p. 113; COSTA, 2008; CYRINO et al., 2005; LEON et al., 1981). Dessa forma, como foi realizado por Gulick e Malone (2011), o teste de campo ("modifield beep test") foi associado ao teste incremental em ciclo ergômetro (i.e. com procedimento "padrão ouro") e contribuiu para a determinação e predição da potência aeróbia máxima em jogadoras de goalball. Na busca por mais especificidade nas análises, as comparações para a validação no presente estudo foram feitas entre um teste proposto (i.e. Fit-Go) e por um esforço máximo baseado no mesmo conteúdo das atividades do Fit-Go. Nesse sentido, a fim de confirmar os índices máximos obtidos no Fit-Go, um esforço de verificação foi utilizado (NOLAN; BEAVEN; DALLECK, 2014). Aplicado pelo menos após 30 minutos de recuperação do último teste realizado, um protocolo 


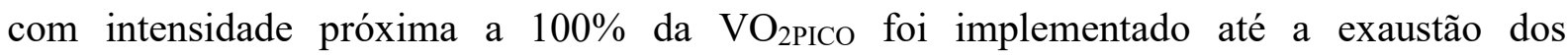
participantes. Ainda assim, o $\mathrm{VO}_{2 \mathrm{PICO}}$ apresentou diferença entre as situações reteste e esforço de verificação e a confirmação da potência aeróbia máxima, por esse método, não foi obtida. Entretanto, a $\mathrm{FC}_{\mathrm{MÁx}}$ e [Lac] $]_{\mathrm{PICO}}$ foram confirmadas no esforço de verificação e, portanto, se mostraram válidas no Fit-Go.

Como parte do processo de validade de um sistema, treinadores de goalball e os jogadores participantes deste estudo foram questionados sobre a razoabilidade e aceitabilidade do Fit-Go (validade do constructo e facial, respectivamente) (CRONBACH, 1998). De maneira informal, questões foram apresentadas durante o desenvolvimento do protocolo e de suas familiarizações: (i) o teste contempla as ações do jogo?; (ii) a presença da bola é relevante?; (iii) a progressão no teste condiz com a progressão da intensidade?; entre outras perguntas. Todos os contatados afirmaram a representatividade do Fit-Go para a aplicação com jogadores de goalball. Os peritos da modalidade certificaram que o protocolo preenchia as necessidades técnicas (i.e. composição pelas quatro ações presentes na auto-organização do jogo: defesa, transição ofensiva, arremesso com a bola e transição defensiva) (MORATO; GOMES; ALMEIDA, 2012) e de um teste progressivo (i.e. aquecimento e aumento progressivo da intensidade ao longo dos estágios até a exaustão) (BENTLEY; NEWELL; BISHOP, 2007).

Treinadores e fisiologistas podem e devem utilizar o Fit-Go como protocolo progressivo máximo para jogadores de goalball. A consistência operacional e temporal das medidas do teste foi comprovada e, por isso, as medidas são confiáveis para a replicação do protocolo. Nesse sentido, a FC e PSE se mostraram de baixo custo para aplicação, são reprodutíveis e apropriadas para o estabelecimento de âncoras fisiológicas para o treinamento. Embora o $\mathrm{VO}_{2 \mathrm{PICO}}$ não tenha sido confirmado no esforço de verificação, a efetividade do FitGo no cumprimento de três ou mais critérios de exaustão foi assegurada e a capacidade de determinar a potência aeróbia máxima foi identificada. Dessa forma, junto à validação do protocolo pelos treinadores e participantes do estudo, nossos achados salientam a possibilidade de identificação de índices físicos relacionados ao desempenho para a avaliação, prescrição e monitoramento de equipes de goalball de nível amador. 


\section{CONSIDERAÇÕES FINAIS}

O conteúdo até aqui apresentado proporciona novos conhecimentos para treinadores, pesquisadores e demais profissionais da área, que têm o intuito de: entender o jogo e suas necessidades táticas, técnicas e físicas emergentes; compreender os aspectos a serem trabalhos com os praticantes; analisar e interpretar o desempenho dos atletas; e criar as condições ideias para o ensino e treinamento da modalidade.

O jogo é complexo, dinâmico, intenso e autorregulado. Seja em competições de nível recreacional, amador ou profissional, duas equipes em um jogo disputam constantemente a obtenção de situações favoráveis para alcançar o sucesso. Você treinador é o responsável por propor, organizar, avaliar, monitorar e prescrever as melhores condições para o ensinoaprendizagem desse esporte Paralímpico. Baseado na teoria do conhecimento interacionista e na abordagem dos constrangimentos, as ações do jogo emergem da interação do ambiente (i.e. o jogo em seus diversos contextos e sentidos), da tarefa (i.e. da sua atividade proposta) e das pessoas (e.g. os praticantes e atletas) (SCAGLIA; REVERDITO; GALATTI, 2014). Por isso, Compreenda o ambiente que você está inserido, isto vai orientar o entendimento das pessoas e a delimitar a aplicação das tarefas na prática.

Na presente dissertação, para a compreensão das ações fortemente inapropriadas ás fortemente apropriadas do jogo de goalball (estudo 1), foram aplicadas análises de jogos advindos de um contexto de alto rendimento (Jogos Paralímpicos). Dessa forma, os indicadores obtidos retratam condições das melhores equipes do mundo. Direcionar a tarefa de acordo com os resultados de equipes bem sucedidas pode estimular a obtenção de resultados favoráveis para sua equipe.

A você treinador, atente-se ao resultado momentâneo da partida. O estado "ganhando" se mostrou uma variável chave para o alto desempenho no jogo. A fase defensiva demonstrou desempenho fortemente apropriado em todas as equipes, independentemente do resultado momentâneo, do resultado da partida e do nível das equipes. Dessa forma, a diminuição do tempo de controle da bola na fase defensiva e, a todo o momento, assegurar não cometer penalidades, são fatores que podem contribuir para a obtenção do sucesso por sua equipe. Interrupções do jogo parecem indicar maiores chances de marcar gol para a equipe com a posse de bola. Adicione estratégias de treinamentos de arremessos entre jogadores ou entre trave e jogadores, principalmente em situações após períodos de interrupção oficial. Ainda, à você pesquisador, tendo em vista que os resultados até aqui apresentados se mostraram diretamente relacionados ao sucesso e as variáveis contextuais na partida, mais investigações 
são necessárias para a compreensão e detalhamento desses indicadores em outros níveis competitivos, sexo, e para incorporação de mais variáveis discriminantes entre as equipes (e.g. velocidade do ataque e da bola).

O entendimento da pessoa, praticante ou atleta que compõe uma equipe delimitam a definição das tarefas (e suas progressões) a serem estabelecidas ao longo dos treinamentos. Para um bom desempenho dos esforços no goalball, sabemos que a manutenção e disposição energética se faz necessário para o alto rendimento das ações. No estudo 2 desta dissertação, foi proposto um protocolo específico, adaptado de outros autores (GULICK; MALONE, 2011), e aplicado em jogadores amadores pertencentes a uma instituição especializada ao atendimento de pessoas com deficiência visual. Nesse contexto, estão dispostas pessoas com intuito de lazer, saúde, rendimento, entre outros objetivos. Independente do nível dos participantes deste estudo (que variou em sete anos), indicadores físicos se mantiveram semelhantes quando aplicados em dias diferentes. Dessa forma, considerando a necessidade de preservação da especificidade no período avaliativo do seu aluno, um teste de campo com concordância processual/temporal na identificação da potência aeróbia máxima e outros índices físicos (e.g. FC), foi desenvolvido e efetivo para a utilização com jogadores de goalball.

A você treinador, compreenda o passo-a-passo para a familiarização e aplicação do teste. Em virtude do alto custo de alguns instrumentos metodológicos, opções de baixo custo, reprodutíveis e de fácil aplicação/obtenção dos resultados foram sugeridas. A você pesquisador, limitações metodológicas possibilitaram os insights para futuras pesquisas: aplicação do teste em larga escala, em diferentes níveis competitivos e sexo; desenvolvimento e análise da reprodutibilidade e validade de um teste físico específico para a determinação da potência anaeróbia alática (i.e. metabolismo determinante nas ações dos jogos de goalball veja também ALVES et al., 2018);

Espero ter potencializado o entendimento do jogo do goalball e, evoluído o saber científico sobre as possibilidades de avaliação do rendimento de atletas de goalball. Ainda, de acordo com Alves, Furtado e Morato (2020, p. 77)

Quase duas décadas de ciência no goalball revelam que ainda somos iniciantes na modalidade. $\mathrm{O}$ goalball carece da prática regular da ciência e da busca pelo alto nível das publicações. Na tentativa de recusar o óbvio em busca do rendimento científico, a promoção de estudos inovadores deve ser cenário para a evolução da modalidade. Esperamos ter demonstrado, acima de tudo, que o goalball avança os limites da quadra, e que, por isso, o treinamento não envolve apenas aspectos táticos, técnicos e físicos. Por trás do jogo do silêncio, vozes de motivação, torcida, diversão e muita ciência fazem do goalball um fenômeno sociocultural contemporâneo. 


\section{REFERÊNCIAS}

AKINOĞLU, B.; KOCAHAN, T.; AKINO, B. Comparison of muscular strength and balance in athletes with visual impairment and hearing impairment. Journal of Exercise Rehabilitation, v. 14, n. 5, p. 765-770, 2018.

ALEXANDRE, N. M. C.; COLUCI, M. Z. O. Validade de conteúdo nos processos de construção e adaptação de instrumentos de medidas. Ciência \& Saúde Coletiva, v. 16, n. 7, p. 3061-3068, 2011.

ALMEIDA, C. H.; FERREIRA, A. P.; VOLOSSOVITCH, A. Effects of match location, match status and quality of opposition on regaining possession in UEFA Champions League. Journal of human kinetics, v. 41, n. 1, p. 203-214, 2014.

ALVES, I. S. et al. Relationships Between Aerobic and Anaerobic Parameters With Game Technical Performance in Elite Goalball Athletes. Frontiers in Physiology, v. 9, n. 1636, p. $1-10,2018$.

ALVES, I. S., FURTADO, O. L. P. C., MORATO, M. P. Goalball: 74 anos de idade e quase duas décadas de ciência. In Boullosa, D., Lara, L., Athayde, P. (Eds.). Treinamento esportivo: um olhar multidisciplinar. EDUFRN, p. 65-81, 2020.

ALtMAN, D.G. (1991). Practical Statistics for Medical Research. London: Chapman \& Hall, p.404.

AMERICAN COLLEGE OF SPORTS MEDICINE. ACSM's guidelines for exercise testing and prescription. 5th Ed. Baltimore: Williams and Wilkins, 1995.

AMORIM, M. et al. Goalball: uma modalidade desportiva de competição. Revista Portuguesa de Ciências do Desporto, v. 10, n. 1, p. 221-229, 2010.

ANGUERA, M. T.; MENDO, A. H. La metodología observacional en el ámbito del deporte. Revista de Ciencias del Deporte, v. 9, n. 3, p. 135-160, 2013.

AQUINO, R. et al. A produção científica acerca do aspecto tático-técnico nos jogos esportivos coletivos: Análise dos periódicos Brasileiros. Movimento, v. 23, n. 4, p. 14071420, 2017.

AQUINO, R. et al. Influence of situational variables, team formation, and playing position on match running performance and social network analysis in brazilian professional soccer players. The Journal of Strength \& Conditioning Research, v. 34, n. 3, p. 808-817, 2020.

ARAÚJO, N. D. et al. Ansiedade pré-competitiva em atletas do campeonato brasileiro de goalball. Coleção Pesquisa em Educação Física, Várzea Paulista, v. 12, n. 4, p. 57-66, 2013. 
ASLAN, C. S.; KARAKOLLUKÇU, M.; ÜRGÜP, S. Effects of Body Composition on Achievement in Goalball. Journal of Physical Fitness, Medicine \& Treatment in Sports, v. 3, p. 1-4, 2018.

ATKINSON, G.; NEVILL M. A. Statistical Methods For Assessing Measurement Error (Reliability) in Variables Relevant to Sports Medicine. Sports Medicine, v. 26, n. 4, p. 217238,1998 .

ATAN, T. AYCA M. Effect of Goalball Sport on Physical Performance of Visually Impaired Students. Journal of Social Science Research, v. 7, n. 1, p. 1206-1212, 2015.

AYDOĞ, E. et al. Dynamic postural stability in blind athletes using the Biodex Stability System. International Journal of Sports Medicine, v. 27, n. 5, p. 415-418, 2006.

BEDNARCZUK, G. et al. Static balance of visually impaired paralympic goalball players. International Journal of Sports Science \& Coaching, v. 12, n. 5, p. 611-617, 2017.

BENTLEY, D. J.; NEWELL, J.; BISHOP, D. Incremental exercise test design and analysis: Implications for performance diagnostics in endurance athletes. Sports Medicine, v. 37, n. 7, p. 575-586, 2007.

BORG, G. A. Psychophysical bases of perceived exertion. Medicine Science Sports and Exercise, v.14, n.5, p.377-381, 1982.

BURGESS, D. J. The Research Doesn' t Always Apply: Practical Solutions to EvidenceBased Training-Load Monitoring in Elite Team Sports. International Journal of Sports Physiology and Performance, v.12, p. 136-141, 2017.

BOWERMAN, S. et al. Phases of movement of goalball throw related to ball velocity. Research and Practice in Visual Impairment and Blindness, Denton, TX. v. 4, n. 4, p. 153-158, 2011.

CALISKAN, E. et al. The Effects of Long Term Goalball Sport on Reaction Times in Blind Children by Sex and Handedness. Neurology Psychiatry and Brain Research, v. 16, n. 3-4, p. $97-100,2010$.

CAMPOS, E. Z. et al. Anaerobic Contribution Determined in Swimming Distances: Relation with Performance. Frontiers in Physiology, v. 8, n. 755, p. 1-6, 2017.

CAPUTO, F. et al. Exercício aeróbio: Aspectos bioenergéticos, ajustes fisiológicos, fadiga e índices de desempenho. Revista Brasileira de Cineantropometria e Desempenho Humano, v. 11, n. 1, p. 94-102, 2009.

CASTELlanO, J.; CASAMICHANA, D.; LAGO, C. The use of match statistics that discriminate between successful and unsuccessful soccer teams. Journal of Human Kinetics, v. 31, n. 1, p. 139-147, 2012.

CAVAZZOTTO, T. G. et al. Efeito da aprendizagem no desempenho de repetidos testes de Wingate. Revista Brasileira de Ciências do Esporte, v. 36, n. 1, p. 59-69, 2014. 
CHAVERRI, D. et al. A new model for estimating peak oxygen uptake based on postexercise measurements in swimming. International Journal of Sports Physiology and Performance, v.11, n.4, p.419-424, 2016.

CYRINO, E. S. et al. Comparação entre a potência aeróbia estimada por dois testes de campo. Journal of Physical Education, v. 16, n. 2, p. 171-177, 2005.

COSTA, I. T. et al. Sistema de avaliação táctica no Futebol (FUT-SAT): Desenvolvimento e validação preliminar. Motricidade, v. 7, n. 1, p. 69-84, 2011.

COSTA E. C. Validade da medida do consumo máximo de oxigênio predito pelo teste de cooper de 12 minutos em adultos jovens sedentários. Motricidade, v.4, n.3, p.5-10, 2008.

ÇOLAK, T. et al. Physical fitness levels of blind and visually impaired goalball team players. Isokinetics and Exercise Science, Kocaeli, Turkey, v. 12, n. 4, p. 247-252, 2004.

COSTA, A. M.; WINCKLER C. A educação física e o esporte paralímpico. In: MELLO, M. T.; WINCKLER C. Esporte Paralímpico. São Paulo: Editora Atheneu, 2012. p. 15-20.

CRONBACH, L. J. Five perspectives on validity argument. In: WAINER, H.; BRAUN, H. I. (Eds.), Test validity. New Jersey: Lawrence Erlbaum Associates, 1998.

DAVIDS, K. Ecological validity in understanding sport performance: some problems of definition. Quest, v. 40, n. 2, p. 126-136, 1988.

EDVARDSEN, E.; HEM, E.; ANDERSSEN, S. A. End criteria for reaching maximal oxygen uptake must be strict and adjusted to sex and age: A cross-sectional study. PLoS ONE, v. 9, n. 1, p. 18-20, 2014.

EDDY, K. A. T.; MELLALIEU, S. D. Mental imagery in athletes with visual impairments. Adapted Physical Activity Quarterly, v. 20, n. 4, p. 347-368, 2003.

EISENMANN, J. C. et al. Comparative analysis of the Cosmed Quark b (2) and K4b (2) gas analysis systems during submaximal exercise. Journal of Sports Medicine and Physical Fitness, v. 43, n. 2, p. 150, 2003.

FERRANNINI, E. The theoretical bases of indirect calorimetry: a review. Metabolism, v. 37, p. 287-301, 1988.

FLEISS, J. L.; LEVIN, B.; PAIK, M. C. Statistical methods for rates and proportions. New York: John Wiley \& Sons, 2013.

FOSTER, C. et al. A new approach to monitoring exercise training. Journal of Strenght and Condittioning Research, v.15, n.1, p.109-115, 2001.

FURTADO, O. L. P. C., MORATO, M. P., POTENZA, M., GUTIERREZ, G. L. Healthrelated physical fitness among young goalball players with visual impairments. Journal of Visual Impairment \& Blindness, v. 110, n. 257, 2016. 
GAWLIK, K.; ZWIERZCHOWSKA, A.; ROSOLEK, B. Evaluation of Lipid Metabolism and Nutritional Status in Male Goalball Players. journal of Human Kinetics, v. 48, n. 1, p. 141$147,2015$.

GIANNICHI, R. S. Medidas e avaliação em Educação Física. Viçosa: Imprensa Universitária, 1984.

GOMES-DA-SILVA, P. N.; ALMEIDA, J. E. A.; ANTÉRIO, D. A Comunicação Corporal No Jogo De Goalball. Movimento, v. 21, n. 1, p. 25-40, 2015.

GOULART-SIQUEIRA, G. et al. Relationships between Different Field Test Performance Measures in Elite Goalball Players. Sports, v. 7, n. 1, p. 1-7, 2019.

GULICK, D. T; MALONE L. A. Field test for measuring aerobic capacity in paralympic goalball athletes. International Journal of Athletic Therapy \& Training, Nova York, v.16, n.5, p. 22-25; sep. 2011.

HAEGELE, J. A.; WIEGEL, W. Goalball Showdown: A Small-Sided Game. Palaestra, v. 32, n. 3, p. 35-38, 2018.

HAEGELE, J. A.; ZHU, X.; DAVIS, S. The meaning of physical education and sport among elite athletes with visual impairments. European Physical Education Review, v. 23, n. 4, p. 375-391, 2017.

HOPKINS, W. G. Measures of reliability in sports medicine and science. Sports Medicine, v. 30, n. 1, p. 1-15, 2000.

HUGHES, M. D.; BARTLETT, Roger M. The use of performance indicators in performance analysis. Journal of Sports Sciences, v. 20, n. 10, p. 739-754, 2002.

JACOBS, I. Blood lactate: Implications for training and sports performance. Sports Medicine, v.3, p. 10-25, 1986.

JEUKENDRUP, A. E.; WALLIS, G. A. Measurement of substrate oxidation during exercise by means of gas exchange measurements. International Journal of Sports Medicine, Supplement, v. 26, n. 1, 2005.

KARAKAYA, İ. Ç.; AKI, E.; ERGUN, N. Physical Fitness of Visually Impaired Adolescent Goalball Players. Perceptual and Motor Skills, v. 108, n. 1, p. 129-136, 2009.

KHOO, S.; LI, C.; ANSARI, P. The top 50 most cited publications in disability sport: A bibliometric analysis. Perceptual and Motor Skills, v. 125, n. 3, p. 525-545, 2018.

KIZAR, O. et al. Comparison of loneliness levels in visually impaired from different sports branches. The Anthropologist, v. 24, n. 3, p. 853-858, 2016.

INTERNATIONAL BLIND SPORTS ASSOCIATION. IBSA Classification Rules. Sport Classes Profiles for Athletes with Vision Impairment, 01 dec. 2018. Disponível em: $<$ http://www.ibsasport.org/documents/files/182-1-IBSA-Classification-rules-2018.pdf $>$. Acesso em: 03/2020. 
LAGO, C. The influence of match location, quality of opposition, and match status on possession strategies in professional association football. Journal of sports sciences, v. 27, n. 13, p. 1463-1469, 2009.

LAREDO, F. R.; RODRÍGUEZ-BIES, E.; LÓPEZ-LLUCH, G. Frecuencia cardíaca y movimientos en goalball: Estudio en una situación de partido. EmásF: revista digital de educación física, n. 56, p. 56-65, 2019.

LARSEN, C. H. Preparing for the European Championships: A six-step mental skills training program in disability sports. Journal of Sport Psychology in Action, v. 5, n. 3, p. 186-197, 2014.

LÉGER, L. A.; SELIGER V.; BRASSARD L. Backward extrapolation of VO2max values from the O2 recovery curve. Medicine And Science in Sports and Exercise, Nova York, v. 12, n. 1, p. 7- 24, 1980.

LEON, A. S. et al. Relationship of physical characteristics and life habits to treadmill capacity. American Journal of Epidemiology, v. 113, n.6, p. 653-60, 1981.

LIBERATI, A. et al. The PRISMA statement for reporting systematic reviews and metaanalyses of studies that evaluate health care interventions: explanation and elaboration. PLoS Medicine, v.6, n.e1000100, 2009.

LIEBERMAN, L. J.; MCHUGH, E. Health-related fitness of children who are visually impaired. Journal of Visual Impairment and Blindness, v. 108, n. 1, p. 272-287, 2001.

LINK, D., WEBER, C. Finding the gap: an empirical study of the most effective shots in elite goalball. PLoS One, v. 13, p. e0196679, 2018.

MCARDLE, W. D.; KATCH, F. I.; KATCH, V. L. Fisiologia do exercício: nutrição, energia e desempenho humano. Dilza Balteiro Pereira de Campos, Patricia Lydie Voeux. 8. ed. - Rio de Janeiro: Guanabara Koogan, 2016.

MAGALHÃES, T. P. et al. Análise cinemática das ações ofensivas no goalball em situação de jogo: deslocamento do jogador e arremesso. In. IV Congresso Paradesportivo Internacional, 2014, Florianólis: Anais eletrônicos. Disponível em: $<$ http://congressoparadesportivo.cpb.org.br/publicacoes.php>. Acesso em: maio/2020.

MARQUES, R. F. R.; GUTIERREZ, G. L.; ALMEIDA, M. A. B. D. Investigação sobre as configurações sociais do subcampo do esporte paralímpico no Brasil: os processos de classificação de atletas. Revista da educação física/UEM, v. 23, n. 4, p. 515-527, 2012.

MCGARRY, T. et al. Sport competition as a dynamical self-organizing system. Journal of Sports Sciences, v. 20, n. 10, p. 771-781, 2002.

MEDBO, J. I.; TABATA, I. Relative importance of aerobic and anaerobic energy release during short-lasting exhausting bicycle exercise. Journal of Applied Physiology, v. 67, n. 5, p. 1881-1886, 1989. 
MOLIK et al. Game performance evaluation in male goalball players. Journal of Human Kinetics, v. 48, n. 22, p. 43-51, 2015.

MONEZI, L. A. et al. Time-motion analysis of goalball players in attacks: differences of the player positions and the throwing techniques. Sports biomechanics, p. 1-12, 2019.

MORATO, M. P. et al. Development and evaluation of an observational system for goalball match analysis. Revista Brasileira de Ciências do Esporte, v. 39, p. 398-407, 2017.

MORATO, M. P. et al. Faster balls increase the probability of scoring a goal in female and male elite goalball. Revista Brasileira de Ciências do Esporte, v. 40, p. 427-434, 2018.

MORATO, M. P.; GOMES, M. S. P.; ALMEIDA, J. J. G. De. Os processos autoorganizacionais do goalball. Revista Brasileira de Ciências do Esporte, v. 34, n. 3, p. 741$760,2012$.

MORROW, J. R.; JACKSON, A. W. How "significant" is your reliability? Research Quarterly for Exercise and Sport, v. 64, n. 3, p. 352-355, 1993.

NASCIMENTO, D. F.; CAMARGO, W. X. Decodificando o goalball para professores e técnicos de educação física adaptada: Fundamentos técnicos. Cadernos de Formação RBCE, v. 3, n. 1, p. 57-74, 2012.

NASCIMENTO, D. F.; CAMARGO, W. X. Sequenciando fundamentos táticos do goalball para professores-técnicos de educação física adaptada: os sistemas de defesa. Cadernos de Formação RBCE, v. 3, n. 2, P. 79-95, 2013.

NOGUEIRA, C.; SHIBATA, J.; GAGLIARDI, J. Comparação do equilíbrio estático e dinamico entre atletas com deficiência visual, praticantes de goalball e atletismo. Revista Brasileira de Ciência e Movimento, v. 17, n. 2, 2009.

NOLAN, P. B.; BEAVEN, M. L.; DALLECK, L. Comparison of intensities and rest periods for $\mathrm{VO} 2 \mathrm{max}$ verification testing procedures. International journal of sports medicine, $\mathrm{v}$. 35, n. 12, p. 1024-1029, 2014.

OLIVEIRA, C. H. S. et al. O Goalball Como Possibilidade De Inclusão Social De Pessoas Com Deficiência Visual. Pensar a Prática, v. 16, n. 1, p. 165-182, 2013.

O’DONOGHUE, P. O. Research methods for sports. Canada: Routledge, 2010.

PÉREZ-TORRALBA, A. et al. Education intervention using para-sports for athletes with high support needs to improve attitudes towards students with disabilities in Physical Education. European Journal of Special Needs Education, p. 1-14, 2018.

ROCHA, L. et al. Estudo estabilométrico do comportamento postural ortostático em praticantes de goalball. Motricidade, v. 2, n. 3, p. 153-158, 2006.

RODRIGUES, A.; BASTOS, L.; PLUS, F. P. Caracterização dos hábitos de ingestão nutricional e composição corporal de atletas masculinos praticantes de goalball, Arquivos em Movimento v. 3, p. 3-17, 2007. 
RODRÍGUEZ, F. A. et al. Validity of postexercise measurements to estimate peak vo2 in 200-m and 400-m maximal swims. International Journal of Sports Medicine, v.38, n.6, p.426-438, 2017.

ROMANOV, R. et al. The Connection Between Certain Morphological Parameters and Results in Goalball Players. International Journal of Morphology, v. 35, n. 4, 2017.

SANTOS, C. et al. Postural control in athletes with different degrees of visual impairment. Journal of Physical Education, v. 29, 2018.

SCAGLIA, A. J.; REVERDITO, R. S.; GALATTI, L. R. A contribuição da pedagogia do esporte ao ensino do esporte na escola: tensões e reflexões metodológicas. In: MARINHO, A.; NASCIMENTO, J. V.; OLIVEIRA, A. A. B (Eds.). Legados do esporte brasileiro. Florianópolis: UDESC, 2014, p. 45-86.

SCHERER, R. L. et al. Morphological profile of goalball athletes. European Journal of Human Movement, v. 28, p. 1-13, 2012.

SCHERER, R. L.; RODRIGUES, L. A.; FERNANDES, L. L. Contribuição do Goalball para a Orientação e Mobilidade sob a Percepção dos Atletas de Goalball. Pensar a Prática, v. 14, n. 3, p. 1-15, 2011.

SEILER, K. S.; KJERLAND, G. Ø. Quantifying training intensity distribution in elite endurance athletes: is there evidence for an "optimal" distribution?. Scandinavian journal of medicine \& science in sports, v. 16, n. 1, p. 49-56, 2006.

SILVA, E. S. S. et al. Gait and functionality of individuals with visual impairment who participate in sports. Gait \& Posture, v. 62, p. 355-358, 2018.

SILVA, G. C. P.; SILVA, I. F.; PEREIRA, V. R. O esporte como meio de desenvolvimento psicomotor de pessoas com deficiência visual. Arquivos de Ciências da Saúde da UNIPAR, v. 4 , n. $2,2000$.

SILVA, G. P. et al. Tempo de reação e a eficiência do jogador de goalball na interceptação/defesa do lançamento/ataque. Motricidade, v. 6, n. 4, p. 13-22, 2010.

SILVA, M. P. M. et al. Aspects of sports injuries in athletes with visual impairment. Revista Brasileira de Medicina do Esporte, v. 17, n. 5, p. 319-323, 2011.

SILVA, P. et al. Shared knowledge or shared affordances? Insights from an ecological dynamics approach to team coordination in sports. Sports Medicine, v. 43, n. 9, p. 765-772, 2013.

SIMIM, M. A. D. M. et al. O estado da arte das pesquisas em esportes coletivos para pessoas com deficiência: uma revisão sistemática. Arquivos de Ciências do Esporte, v. 6, n. 1, p. 5$10,2018$.

SPENCER, M. et al. Physiological and metabolic responses of repeated-sprint activities. Sports Medicine, v. 35, n. 12, p. 1025-1044, 2005. 
STAMOU, E. et al. The effect of self-talk on the penalty execution in goalball. British Journal of Visual Impairment, v. 25, n. 3, p. 233-247, 2007.

TAYLOR, B. J. et al. Situation variable effects and tactical performance in professional association football. International Journal of Performance Analysis in Sport, v. 10, n. 3, p. 255-269, 2010.

TAYLOR, J. B. et al. The influence of match location, quality of opposition, and match status on technical performance in professional association football. Journal of Sports Sciences, v. 26, n. 9, p. 885-895, 2008.

THEOPHILOS, P. et al. Heart rate responses and blood lactate concentration of goal ball players during the game. In: 10th Annual Congress of the European College of Sport Science, 2005, Belgrado-Servia: Anais eletrônicos. Disponível em: $<$ http://www.smas.org/2kongres/papers/14521.pdf>. Acesso em: abril/2020.

TINDALL, D. W. et al. Physical activity levels of children with visual impairments during adapted sports camp. British Journal of Visual Impairment, v. 35, n. 2, p. 143-153, 2017.

TINDALL, D.; FOLEY, J.; LIEBERMAN, L. Incorporating sport education roles for students with visual impairments and blindness as part of a sport camp experience. Palaestra, v. 30, n. $3,2016$.

THOMAS, J. R.; NELSON, J. K.; SILVERMAN, S. J. Métodos de pesquisa em atividade física. 6. ed. Porto Alegre: Artmed, 2012.

TOSIM, A. et al. Sistemas técnicos e táticos no goalball. Revista Mackenzie de Educação Física e Esporte, São Paulo, v.7, n.2, p.141-148, 2008.

VALDÉS, B. P. A.; GODOY, C. A. E. R.; HERRERA, V. T. N. Somatotipo, composición corporal, estado nutricional y condición física en personas con discapacidad visual que practican goalball. International Journal of Morphology, v. 32, n. 1, p. 183-189, 2014.

VAN RHEENEN, D. The Blind Leading the Blind: Goalball as Engaged Scholarship. Journal of Postsecondary Education and Disability, v. 29, n. 1, p. 25-34, 2016.

VANLANDEWIJCK, Y. Sporty science in the Paralympic movement. Journal of Rehabilitation Research and Development, v.43, n.7, p.12-20, 2006.

VELASCO, A.; DOS SANTOS, S. M.; DE SOUZA, D. L. Os significados da prática do Goalball sob a ótica de atletas da modalidade. The Journal of the Latin American Sociocultural Studies of Sport (ALESDE), v. 8, n. 1, p. 43-58, 2018.

WATT, K.; HOPKINS, W. G.; SNOW, R. J. Reliability of performance in repeated sprint cycling tests. Journal of Science and Medicine in Sport, v. 5 n. 4. p. 354-361, 2002. 
APÊNDICE 1

(continua)

\section{TERMO DE CONSENTIMENTO LIVRE E ESCLARECIDO}

Eu, Isabella dos Santos Alves, aluna do Programa de Pós-Graduação - Educação Física e Esporte da Escola de Educação Física e Esporte de Ribeirão Preto EEFERP/USP, orientada pelo Prof. Dr. Márcio Pereira Morato, estou convidando você para participar como voluntário do estudo que estou realizando, intitulado: "Análise do Desempenho no Goalball: Proposta de Avaliações Específicas".

Peco que fique atento à leitura das explicacões antes de preenchermos as informacões e assinarmos o documento

- JUSTIFICATIVA E OBJETIVOS: No goalball, um esporte desenvolvido para pessoas cegas e com baixa visão, o desempenho tático-técnico ainda é pouco explorado na literatura quando comparado com índices de aptidão física. Esta que, geralmente é avaliada em situação não específica, violando o pressuposto de validade ecológica do jogo. Assim, o objetivo geral do projeto é elaborar e propor avaliações específicas para análise do desempenho tático-técnico e físico em jogadores de goalball.

- LOCAL DE REALIZAÇÃo: A pesquisa será realizada preferencialmente na quadra do ginásio poliesportivo da EEFERP/USP ou, caso necessário na cidade de Jundiaí/SP, local de treinamento da equipe de goalball.

- PROCEDIMENTOS A SEREM REALIZADOS: Serão propostas e aplicadas avaliações em dois contextos e dias diferentes: Avaliação em jogo simulado e em teste físico em quadra. Na avaliação em jogo, você será filmado para contagem de ações e verificação da qualidade das mesmas. Além disso, no início, ao final do primeiro tempo e final do jogo haverá pausas para avaliação física: análise do ar expirado em uma máscara específica, coleta de sangue do lóbulo orelha do lado de sua preferência $(25 \mu \mathrm{L})$, frequência cardíaca (utilização de uma fita sensorizada na região torácica) e percepção subjetiva de esforço (escala autorrelatada, sendo 0 sensação de repouso e 10 sensação de esforço máximo). Todos os procedimentos serão realizados por profissionais capacitados. Já no teste físico em quadra, você vai ser familiarizado com uma sequência de três ações específicas do goalball: defesa (Ação 1), preparação do ataque (Ação 2) e arremesso (Ação 3). Esta sequência deverá ser executada com tempo pré-determinado durante estágios de 180 segundos. O objetivo principal é aumentar a velocidade de execução das ações de maneira progressiva. Importante destacar que a mesma avaliação física realizada no jogo, será realizada entre cada estágio, por um período máximo de 30 segundos.

- DESCONFORTOS E POSSÍVEIS RISCOS: Os riscos da participação neste estudo, apesar de raros, são inerentes a qualquer prática de atividade física de alta intensidade, tais como os encontrados na rotina diária de treinamento. São exemplos eventuais desconfortos resultantes do estresse físico e psicológico característico da situação de elevada acidose metabólica, como náuseas e cefaleias. Também poderão aparecer hematomas e edemas resultantes das coletas de sangue feitas pelo lóbulo da orelha. No entanto, todos os pesquisadores envolvidos no experimento possuem treinamento em suporte básico de vida e serão tomadas medidas de segurança, como 
treinamento de sinais de segurança (tátil e sonoro devido à deficiência visual) para a comunicação durante os testes.

- RECUSA/ABANDONO DA PESQUISA: Caso você não queira participar de alguma etapa das coletas, ou desista totalmente de participar a qualquer momento, sua decisão será respeitada sem que isto acarrete em multas/prejuízos ou algo do tipo.

- SIGILO: Os resultados da pesquisa serão publicados em revista científica de forma global, com valores de médias ou percentuais dos resultados de todos os participantes. Os nomes não serão divulgados de maneira alguma, garantindo assim a sua privacidade e sigilo.

- DESPESAS: A pesquisa não envolverá nenhum custo financeiro para os participantes. Igualmente o caráter voluntário também não dá direito de alguma forma de pagamento pela participação. Porém, haverá ressarcimento diante de eventuais despesas (tais como transporte e alimentação), quando necessário.

- BENEFÍCIOS QUE PODERÃO SER OBTIDOS: Você receberá cópia dos resultados obtidos nos testes, com uma estimativa detalhada da avaliação física nos teste de campo, e desempenho tático-técnico observado em jogo. Ambas as informações serão de extrema relevância ao treinador e analistas de desempenho, que utilizarão das variáveis como forma de avaliação, monitoramente e prescrição para o ciclo de treinamento em que a equipe se encontra.

- INDENIZAÇÃO: Diante de eventuais danos decorrentes da pesquisa você terá direito a indenização conforme as leis vigentes no país.

- DÚVIDAS: A qualquer momento, as dúvidas de procedimentos, objetivos ou qualquer assunto relacionado ao estudo poderão ser esclarecidos pessoalmente com a pesquisadora responsável, ou pelos seguintes contatos: e-mail isabella.santos.alves@usp.br; ou telefone (16) 99158-4842 (Claro). Ainda, é possível contatar a secretaria do Comitê de Ética da Escola de EEEFERP/USP pelos seguintes contatos: e-mail mtreviso@usp.br; ou telefone (16) 3315-0494.

\section{Por fim, esse documento será assinado por nós em duas vias de} igual teor, sendo uma sua e a outra minha.

$\mathrm{Eu}$

após ter sido informado de todas as etapas da pesquisa e esclarecido dos riscos, direitos e participação envolvida, declaro que concordo participar voluntariamente da pesquisa. 
ANEXO 1

(continua)

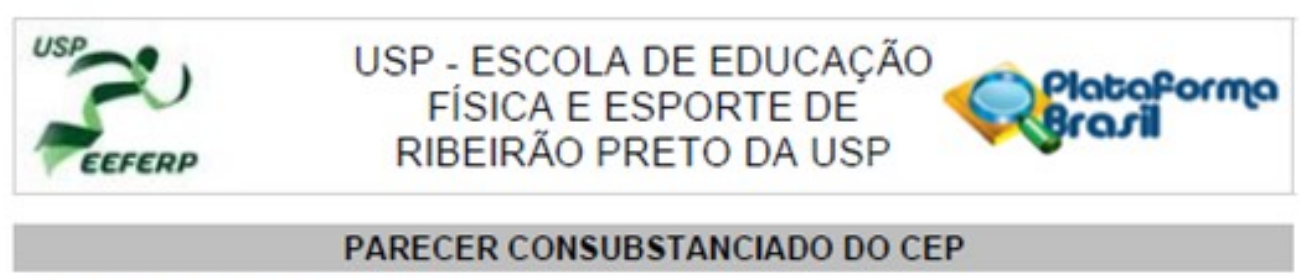

DADOS DO PROJETO DE PESQUISA

Titulo da Pesquisa: Análise do Desempenho no Goalball: Proposta de Avaliaçōes Especificas

Pesquisador: Isabella dos Santos Alves

Área Temática:

Versão: 1

CAAE: 93692318.0 .0000 .5659

Instituição Proponente: UNIVERSIDADE DE SAO PAULO

Patrocinador Principal: UNIVERSIDADE DE SAO PAULO

DADOS DO PARECER

Número do Parecer: 2.808 .287

Apresentação do Projeto:

Trata-se do projeto de Mestrado da discente Isabella dos Santos Alves, intitulado "Análise do Desempenho no Goalball: Proposta de Avaliações Específicas", sob orientação do Prof. Dr. Márcio Pereira Morato.

Objetivo da Pesquisa:

"Elaborar e propor dois métodos de avaliação do desempenho para jogadores de goalball, o primeiro para análise notacional dos aspectos tático-técnicos em situação do jogo, e o segundo, para determinação da potência aeróbia dos atletas"

Avaliação dos Riscos e Beneficios:

Riscos: "apesar de raros, são inerentes a qualquer prática de atividade física de alta intensidade, tais como os encontrados na rotina diária de treinamento. São exemplos eventuais desconfortos resultantes do estresse físico e psicológico caracteristico da situação de elevada acidose metabólica, como náuseas e cefaleias. Também poderão aparecer hematomas e edemas resultantes das coletas de sangue feitas pelo lóbulo da orelha",

Beneficios: "Cada participante receberá uma cópia dos resultados obtidos nos testes, com uma estimativa detalhada do indice aeróbio verificado em teste específico, e desempenho tático-técnico observado em jogo. Ambas as informações serão de extrema relevância ao treinador e analistas de desempenho, que utilizarão das variáveis como forma de avaliação, monitoramento e

Endereç: : Avenida Bandeirantes, 3900

Bairro: VILA MONTE ALEGRE

CEP: 14.040 .907

Telefone: (16)3315-0404

E-mail: cepeogusp.br 
(continuação)

\begin{tabular}{|c|c|}
\hline USPFERP & $\begin{array}{c}\text { USP - ESCOLA DE EDUCAÇÃO } \\
\text { FISICA E ESPORTE DE } \\
\text { RIBEIRÃO PRETO DA USP }\end{array}$ \\
\hline
\end{tabular}

prescrição para o ciclo de treinamento em que a equipe se encontra".

Comentários e Consideraçōes sobre a Pesquisa:

Bibliografia atualizada e projeto de extrema pertinència à área em questão.

Apresenta delineamento experimental bem definido e detalhado no projeto de pesquisa.

Considerações sobre os Termos de apresentação obrigatória:

Todos os documentos estão em conformidade com as exigèncias deste CEP.

Recomendaçöes:

Numerar as páginas do TCLE;

Conclusões ou Pendências e Lista de Inadequações:

Vide recomendações

Considerações Finais a critério do CEP:

O projeto encontra-se APROVADO para execução. Pedimos atenção aos seguintes itens:

1) De acordo com a Resolução CNS n. ${ }^{\circ} 466 / 2012$, o pesquisador deverá apresentar relatónios semestrais (parciais e final, em função da đuração da pesquisa);

2) Eventuais emendas (modificaç̋̃es) ao protocolo devem ser apresentadas, com justificativa, ao CEP de forma clara e sucinta, identificando a parte do protocolo a ser modificada. Neste caso, o pesquisador deve aguardar nova aprovação do CEP para realizar os procedimentos de acordo com as mudanças solicitadas;

3) Sobre o TCLE: caso o termo tenha DUAS páginas ou mais, lembramos que no momento da sua assinatura, tanto $\circ$ participante da pesquisa (ou seu representante legal) quanto $\circ$ pesquisador responsável deverão RUBRICAR todas as folhas, colocando as assinaturas na última página;

4) Caso haja instituição(ões) coparticipante(s) no projeto, atender a solicitação da carta n, ${ }^{\circ}$ $0212 / C O N E P / C N S$, de 21 de outubro de 2010;

5) GARANTIR QUE NOS MOMENTOS DE ATIVIDADE FISICA SEMPRE HAJA PELO MENOS UM MEMBRO DA EQUIPE DE PESQUISA APTO A PRESTAR OS SOCORROS DE URGĖNCIA, INCLUSIVE MASSAGEM CARDIACA E USO DO DEA, CASO NECESSÁRIO. 
(continuação)

\begin{tabular}{|c|c|c|c|c|}
\hline USP & \multicolumn{2}{|c|}{$\begin{array}{c}\text { USP - ESCOLA DE EDUCAÇÃO } \\
\text { FÍSICA E ESPORTE DE } \\
\text { RIBEIRÃO PRETO DA USP }\end{array}$} & $\begin{array}{ll}\text { Eofi } \\
\text { sil }\end{array}$ & a \\
\hline \multicolumn{5}{|c|}{ Corthuaplo do Pareser: 2809.287} \\
\hline \multicolumn{5}{|c|}{ Este parecer foi elaborado baseado nos documentos abaixo relacionados: } \\
\hline Tipo Documento & Arquivo & Postagem & Autor & Situação \\
\hline $\begin{array}{l}\text { Informaçōes Básicas } \\
\text { do Projeto }\end{array}$ & $\begin{array}{l}\text { PB_INFORMAÇOEES_BÁSICAS_DO_P } \\
\text { ROJETO } 1162759 \text { pdf }\end{array}$ & $\begin{array}{l}11 / 07 / 2018 \\
17: 25: 47\end{array}$ & & Aceito \\
\hline $\begin{array}{l}\text { TCLE / Termos de } \\
\text { Assentimento / } \\
\text { Justificativa de } \\
\text { Ausências }\end{array}$ & TCLE_Isabella.docx & $\begin{array}{l}11 / 07 / 2018 \\
17: 24: 13\end{array}$ & $\begin{array}{l}\text { Isabella dos Santos } \\
\text { Alves }\end{array}$ & Aceito \\
\hline $\begin{array}{l}\text { Projeto Detalhado / } \\
\text { Brochura } \\
\text { Investigador }\end{array}$ & Projeto_Isabella.docx & $\begin{array}{l}11 / 07 / 2018 \\
17: 23: 46\end{array}$ & $\begin{array}{l}\text { Isabella dos Santos } \\
\text { Alves }\end{array}$ & Aceito \\
\hline Orçamento & Orcamento_Isabella.docx & $\begin{array}{l}11 / 07 / 2018 \\
17: 21: 31\end{array}$ & $\begin{array}{l}\text { Isabella dos Santos } \\
\text { Alves }\end{array}$ & Aceito \\
\hline Cronograma & Cronograma_Isabella.docx & $\begin{array}{c}11 / 07 / 2018 \\
17: 21: 18\end{array}$ & $\begin{array}{l}\text { Isabella dos Santos } \\
\text { Alves }\end{array}$ & Aceito \\
\hline Follha de Rosto & Folha_de_Rosto_Isabella.pdf & $\begin{array}{c}11 / 07 / 2018 \\
17: 20: 10\end{array}$ & $\begin{array}{l}\text { Isabella dos Santos } \\
\text { Alves }\end{array}$ & Aceito \\
\hline
\end{tabular}

Situação do Parecer:

Aprovado

Necessita Apreciação da CONEP:

Não

RIBEIRAO PRETO, 08 de Agosto de 2018

Assinado por:

Carlos Roberto Bueno Júnior

(Coordenador)

Endereso: Avenida Bundeirantes, 3900

Eairro: VILA MONTE ALEGRE

Municipio: RIBEIRAO PRETO

CEP: $14040-907$

Telefone: (16)3315-0494

E-mail: cepeogusp.br 